\title{
Borate-assisted liquid-phase selective oxidation of $\boldsymbol{n}$-pentane
}

Samson M. Aworinde, ${ }^{\mathrm{a}}$ Kun Wang, ${ }^{\mathrm{b}}$ Alexei A. Lapkin ${ }^{\mathrm{a}, *}$

a Department of Chemical Engineering and Biotechnology, University of Cambridge, Philippa Fawcett Drive, Cambridge, CB3 OAS, United Kingdom

${ }^{\mathrm{b}}$ Corporate Strategic Research, ExxonMobil Research and Engineering Company, 1545 US22 East, Annandale, NJ 08801, United States

\section{Abstract}

Oxidation of $n$-pentane with molecular oxygen to sec-pentanols was performed in the presence of a free radical initiator (di-tert-butyl peroxide) and a boron compound (sec-butyl metaborate), with in situ adsorption of water on molecular sieve 3A. Kinetics of the reaction was studied in a laboratory-scale batch reactor over a broad range of conditions $\left(130-150^{\circ} \mathrm{C}, 20-30 \mathrm{bar}, 5-10\right.$ vol $\% \mathrm{O}_{2}$ ) in order to establish the optimum parameters for maximising the selectivity and yield of sec-pentanols. Results show that the initiator markedly improves the rate of oxidation, and hence yield, compared to thermal oxidation without an initiator, while the boron species enhances the selectivity to sec-pentanols. Under the conditions investigated, maximum secpentanol selectivity is $56 \%$ with an alcohol-to-ketone ratio of 3.6:1 for the borate-assisted oxidation compared to $33 \%$ and 1.1:1, respectively, for the oxidation without borate. This work demonstrates the feasibility of oxyfunctionalization of $n$-pentane with industrially relevant selectivity and yield.

Keywords: Selective oxidation; $n$-pentane; borate ester; initiator; selectivity

\section{Introduction}

Light paraffins, such as $\mathrm{C}_{4}$ and $\mathrm{C}_{5}$ alkanes, are abundant hydrocarbon resources that are key components of liquefied petroleum gas (LPG) and naphtha. In recent times, stricter government regulations have been introduced to minimise the evaporative emission of volatile organic compounds from motor vehicles as well as upstream and mid-stream gasoline vapour emissions from distribution and storage systems, which cause air pollution problems, including high ground-level ozone or smog. One approach that has been adopted is the control of Reid Vapour Pressure (RVP), which is a measure of gasoline volatility. New environmental regulations impose strict specifications on refiners for the level of light hydrocarbons which can be present in gasoline blends to meet emission targets. The drive towards low-RVP and high-octane fuels

*Corresponding author. E-mail address: aal35@ cam.ac.uk (A.A. Lapkin) 
has increased the availability of $\mathrm{C}_{4}$ and $\mathrm{C}_{5}$ alkanes, consequently, there is considerable interest from the petrochemical industry in novel processes for the upgrading and conversion of these low-cost hydrocarbon feedstocks into chemicals of higher commercial value.

Developments in catalysis and process design has led to industrial-scale exploitation of $n$ butane for the production of maleic anhydride and acetic acid through catalytic gas-phase and liquid-phase selective oxidations, respectively [1,2]. $n$-Pentane, on the other hand, has so far not witnessed the same level of large-scale oxyfunctionalization application. Currently, $n$ pentane is mostly processed by steam cracking at high temperatures to make olefins by dehydrogenation [3]. A significant disadvantage of this process is that it is highly endothermic, requiring temperatures in the range of $500-800^{\circ} \mathrm{C}$ to drive the reactions towards olefins, and is therefore very energy intensive. There are a few reported routes for the transformation of $n$ pentane via oxidation, as shown in Scheme 1. These include oxidative dehydrogenation to 1and 2-pentenes [4], and selective oxidation to a mixture of phthalic and maleic anhydrides $[5,6]$. These two processes are gas-phase heterogeneous catalytic oxidation reactions, which take place at $350-500^{\circ} \mathrm{C}$. A third option is the direct oxidation of $n$-pentane in the liquid phase with molecular oxygen at temperatures in the range of $100-150^{\circ} \mathrm{C}$, with or without a catalyst, into oxygenated products, such as alcohols and ketones. Despite the potential economic value of these approaches, there are currently no practical industrial applications of any of these routes for the conversion of $n$-pentane.

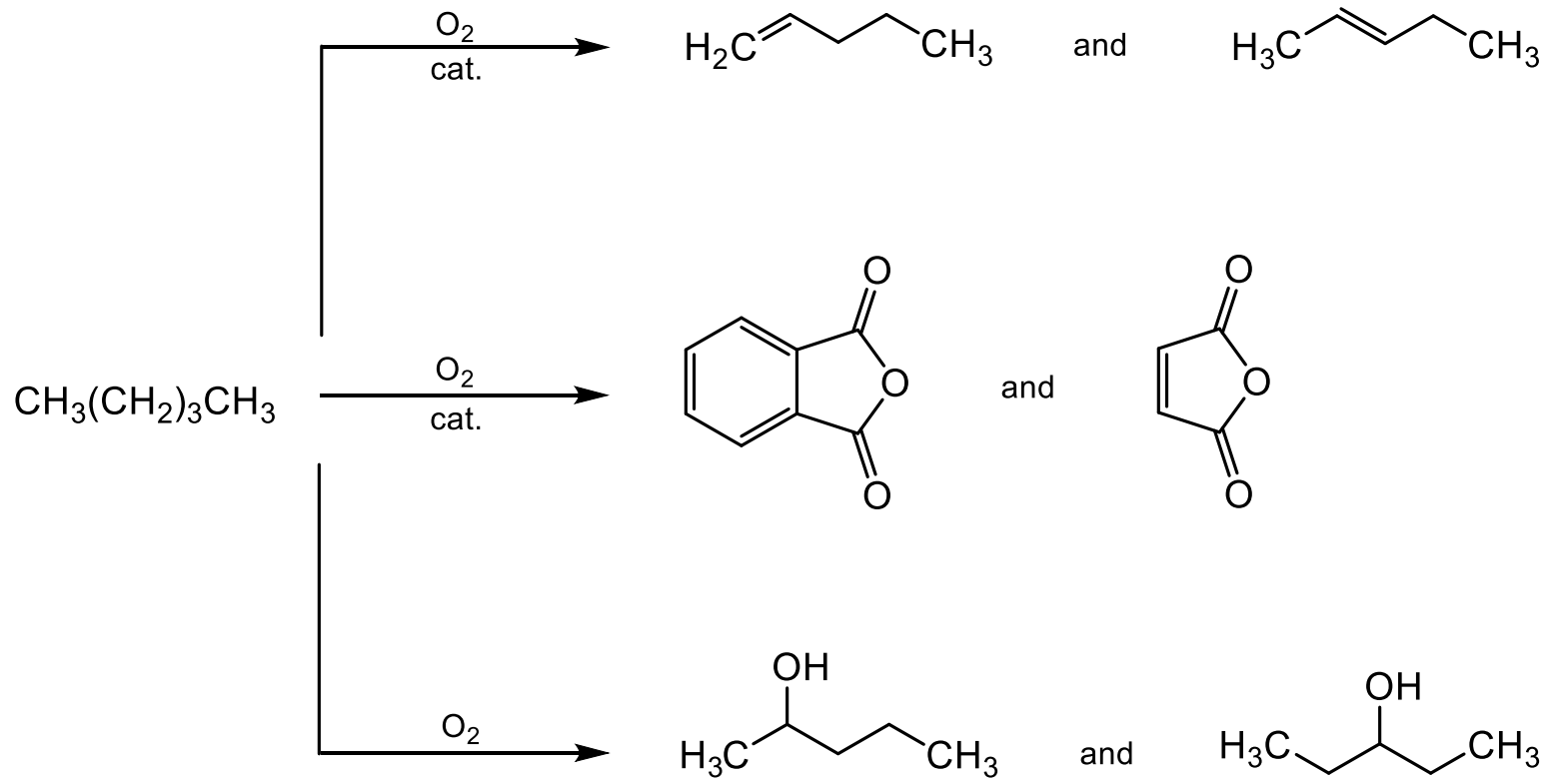

Scheme 1. Potential routes for the conversion of $n$-pentane to petrochemicals. 
The liquid-phase oxidation of $n$-pentane to alcohols and ketones is a significant challenge. One of the main issues with the activation of $n$-pentane, like other light alkanes, is its low reactivity [7]. Small chain alkanes are considerably more difficult to oxidise than longer-chain alkanes as shown by the rate of oxygen uptake in Table 1 . Reactivity increases with decreasing $\mathrm{C}-\mathrm{H}$ bond strength as chain length increases [1,8]. As a result of its relatively low reactivity compared to higher alkanes, the oxidation of $n$-pentane under typical conditions of liquid-phase reactions gives conversion that is too low for commercial exploitation.

A second issue is that the process is typically limited by poor selectivity to alcohols. Selectivity is challenging for two reasons. Liquid-phase oxidations are free radical reactions, which are indiscriminate, with oxidative attack on all reactive $\mathrm{C}-\mathrm{H}$ groups in the alkane molecule. Consequently, for alkanes with more than four carbon atoms such as $n$-pentane, a complex mixture of oxygenated products is formed, including hydroperoxides, alcohols, ketones, carboxylic acids, and esters with all possible isomers. Furthermore, the desired alcohols are more reactive than the starting alkane, and are thus more readily over-oxidised into ketones and acids. Hence, the oxidation process offers little control over alcohol selectivity $[9,10]$.

Table 1. Relative oxidation rates of different linear alkanes [1,11].

\begin{tabular}{cc}
\hline$n$-Alkane & Relative oxidation rate \\
& $\left(\right.$ oxidation rate $\left.=\frac{\mathrm{mol} \mathrm{O}_{2}}{(\mathrm{~mol} \text { alkane }) \times \text { time }}\right)$ \\
\hline Ethane & 0.001 \\
Propane & 0.1 \\
Butane & 0.5 \\
Pentane & 1.0 \\
Hexane & 7.5 \\
Octane & 200 \\
Decane & 1380 \\
\hline
\end{tabular}

A number of studies have been published in the literature on the liquid-phase oxidation of $n$ pentane, largely involving the application of transition metal-based homogeneous and heterogeneous catalysts [12-15]. Despite these attempts, however, none of the reported studies has attained pentane conversion and selectivity to alcohols that are high enough for industrial 
exploitation. It is evident, therefore, that the direct oxidation of $n$-pentane to alcohols with high selectivity and yield continues to be a challenge.

There are a number of strategies for enhancing the selectivity of partial oxidation reactions [16]. One concept that has been reported for improving alcohol selectivity in alkane oxidations is the Bashkirov process, which involves the use of boron compounds such as boric acid, boric oxide and borate esters [17-19]. These boron species function as Lewis acids which direct the oxidation towards the formation of alcohols, and subsequently trap the alcohols in the form of borate esters to protect them from over-oxidation [20-24]. This idea formed the basis of several industrial-scale processes for the oxidation of cyclohexane to cyclohexanol/cyclohexanone, used as intermediate for the production of nylon- 6 , oxidation of cyclododecane to cyclododecanol/cyclododecanone used as intermediates for nylon-12, as well as the oxidation of $\mathrm{C}_{10}-\mathrm{C}_{20}$ alkanes for the synthesis of higher aliphatic alcohols used in the manufacture of detergents and surfactants $[20,25,26]$. The borate-assisted oxidation process allows higher selectivity to be achieved at relatively high feed conversions compared to typical autoxidations, which are normally carried out at low conversions in order to keep selectivity at an acceptable level. For example, during cyclohexane oxidation in the presence of boric acid, conversion of $10-15 \%$ can be achieved with a combined alcohol and ketone selectivity of $90 \%$ and alcohol to ketone ratio of up to 10:1. In the absence of boric acid, the combined selectivity to cyclohexanol and cyclohexanone is $60-70 \%$ with alcohol-to-ketone ratio of $1: 1$ and $4-5 \%$ conversion $[17,21]$.

Although borate-assisted alkane oxidation was performed commercially for high boiling alkanes, this concept has so far not been successfully applied to light alkanes such as $n$-pentane. One of the main constraints is removal of the water formed under reaction conditions, given the high susceptibility of borate esters to hydrolysis in the presence of moisture. Thus, to achieve high selectivity there is a need for effective removal of water from the reaction zone under elevated pressure [27-29]. A second issue is the fact that the low reactivity of light alkanes coupled with the inhibiting action of boron on the oxidation through a reduction in the concentration of free radicals, may result in a substantially lower yield of products.

In this study, we addressed the issue of low reactivity of alkanes and removal of water in the successful attempt to develop a process for selective oxidation of $n$-pentane. 


\section{Mechanism of liquid-phase oxidation of $\boldsymbol{n}$-pentane}

The liquid-phase oxidation of hydrocarbons is a free radical reaction which has been extensively studied and reviewed [1,26,30]. Mechanistically, the reaction involves chain initiation, propagation and termination [31-34]. The complex reaction pathway for the oxidation of $n$-pentane can be summarised by the scheme in Scheme 2. In the thermally initiated reaction, formation of radical by hydrogen atom abstraction from pentane is the slow step and the reaction kinetics exhibits typical sigmoidal behaviour of an autocatalytic process. In this work the addition of a radical initiator DTBP increases the rate of the initial radical formation. Thus, initiation of the oxidation occurs by thermal homolytic decomposition of DTBP through cleavage of the $\mathrm{O}-\mathrm{O}$ bond to give tert-butoxy radicals, which abstract hydrogen atom from secondary $\mathrm{C}-\mathrm{H}$ groups in $n$-pentane leading to formation of sec-pentyl radicals and tert-butyl alcohol. Rapid reaction of the sec-pentyl radicals with molecular oxygen occurs to give secpentylperoxy radicals, which subsequently abstract hydrogen from $n$-pentane to form sec-pentyl hydroperoxide and sec-pentyl radicals. Rupture of the $\mathrm{O}-\mathrm{O}$ bond in the resulting sec-pentyl hydroperoxides takes place, either by unimolecular or bimolecular reactions, to give secpentoxy and hydroxy radicals, followed by fast abstraction of hydrogen atoms from $n$-pentane to give sec-pentanols and water, respectively, as well as radicals, which further propagate the chain process. The sec-pentylperoxy radicals may also interact to form sec-pentoxy radicals and oxygen [31,35] or undergo bimolecular termination reactions to yield sec-pentanols, pentanones and oxygen.

Besides the main reactions, a number of secondary reactions also take place. sec-Pentoxy radicals formed by decomposition of sec-pentyl hydroperoxides can undergo $\beta$-scission or $\mathrm{C}$ C cleavage reactions to give aldehydes, mainly acetaldehyde and propionaldehyde. The aldehydes formed are subsequently oxidised to carboxylic acids, mainly acetic and propionic acids. The free radicals generated carry on the chain by reacting with oxygen to form peroxy radicals or they can abstract hydrogen atom to form smaller chain hydrocarbons such as $\mathrm{CH}_{4}, \mathrm{C}_{2} \mathrm{H}_{6}$ and $\mathrm{C}_{3} \mathrm{H}_{8}$. Furthermore, sec-pentanols can be consecutively oxidised to pentanones, the ketones themselves being further oxidised to carboxylic acids $[1,36]$.

According to several investigators [22,37-40], it has been suggested that during the borateassisted oxidation of alkanes, a coordinatively bonded complex is formed between the boron atom and unpaired electrons on the oxygen atom of the intermediate alkyl hydroperoxide, as illustrated in Scheme 3. The unstable complex may subsequently decompose homolytically into 
145 free radicals such as $\mathrm{R}_{1} \mathrm{O}^{\bullet}$ and $\mathrm{HO}^{\circ}$, which further propagate the oxidation, or it can undergo 146 heterolytic decomposition resulting in the formation of molecular products, mainly alcohols. 147 Itskovich et al. [22] estimated that only $10-15 \%$ of the overall decomposition of a 148 hydroperoxide goes into the formation of free radicals. The main direction of hydroperoxide 149 decomposition in the presence of boron compounds is through a non-radical path which 150 substantially favours alcohol formation, and the lower level of free radicals explains the 151 observed inhibition of the oxidation [41-43]. Furthermore, in the presence of borate, the 152 hydrocarbon solvent is directly hydroxylated to the corresponding alcohol, presumably by the 153 free active oxygen or by electrophilic substitution reaction $[23,40,44]$. 


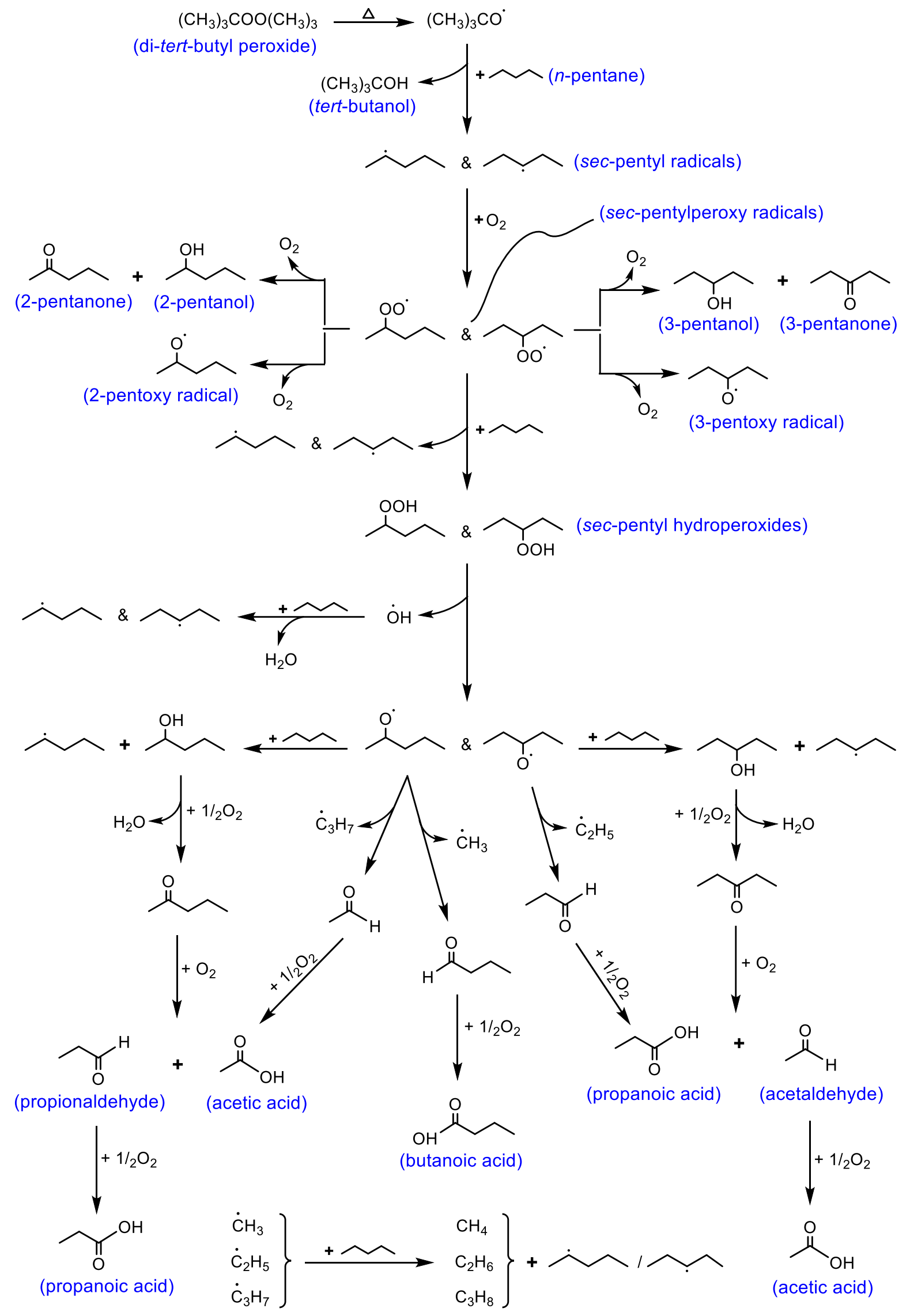

Scheme 2. Reaction scheme for the liquid-phase oxidation of $n$-pentane. 
<smiles>[R]OB1OB([R])OB([R])O1</smiles><smiles>[R]OO[B-]1([R9])OB([R])OB(O[R])O1</smiles>

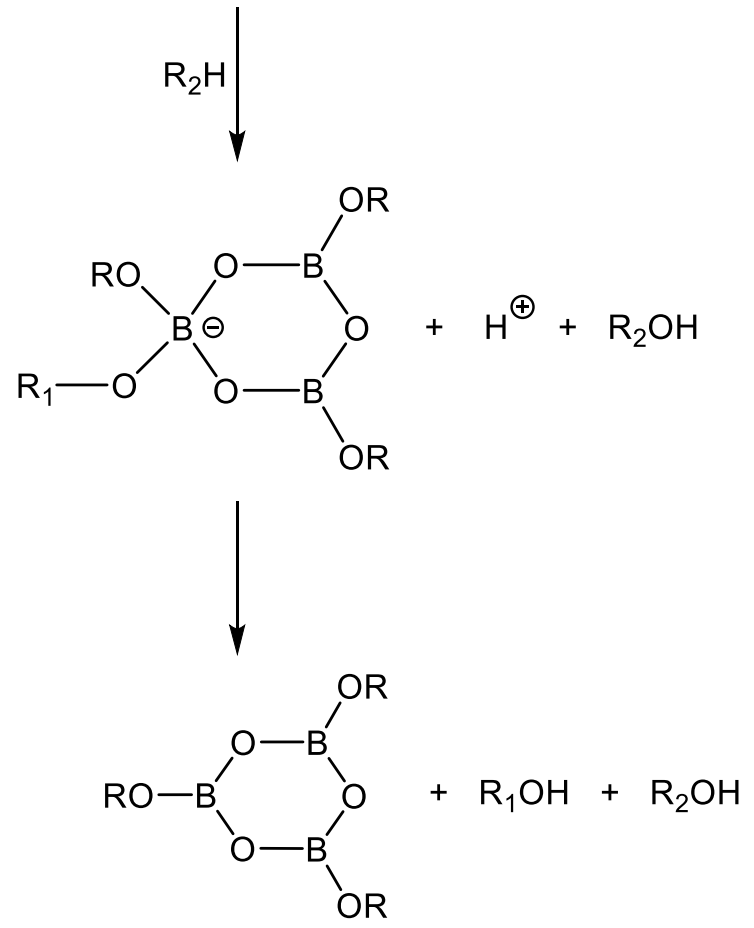

Scheme 3. Mechanism of action of boron on hydroperoxide decomposition during alkane oxidation. $\mathrm{R}_{1} \mathrm{OOH}$ : hydroperoxide, $\mathrm{R}_{2} \mathrm{H}$ : solvent, $(\mathrm{ROBO})_{3}$ : alkyl metaborate.

\section{Experimental}

The kinetic investigation of the liquid-phase oxidation of $n$-pentane with molecular oxygen in the presence of a free radical initiator and boron compounds was carried out in a batch reactor with continuous flow of the gas phase, details of materials and method of which are described below.

\subsection{Materials}

Anhydrous $n$-pentane (99.9\%), di-tert-butyl peroxide (DTBP; Luperox $\left.{ }^{\circledR}, 98 \%\right), 1,4$ difluorobenzene ( $\geq 99 \%$ ), ethyl acetate $(99.8 \%)$, boric oxide (99.98\% trace metal basis), molecular sieve 3A (4-8 mesh beads; Honeywell UOP), silica gel (60 Å pore size, 35-60 mesh particle size) and activated basic alumina (58 Å pore size, 150 mesh particle size) were sourced from Sigma-Aldrich. Triisopropyl borate (TiPrB; AcroSeal ${ }^{\mathrm{TM}}$, $>98 \%$ ) and molecular sieve 3A 
(4-8 mesh beads) were purchased from ACROS Organics (Fisher Scientific, UK). sec-Butyl metaborate $(s-\mathrm{BuMB} ;>98 \%)$ was custom-synthesised and supplied by Tyger Scientific, NJ, USA. The oxidising gas consists of a mixture of oxygen and nitrogen with 5-10 vol\% oxygen (BOC Gases, UK).

171

Prior to oxidation, the anhydrous $n$-pentane was further purified to remove trace impurities such as aromatic compounds, olefins, water and oxygen-containing compounds which may interfere with the reaction and subsequent analyses. The received $n$-pentane was treated by percolating it through a packed column containing $\sim 100 \mathrm{~g}$ of silica gel and $\sim 100 \mathrm{~g}$ of activated basic alumina in a specially built glass apparatus under argon. Both silica gel and alumina were previously heated to $300^{\circ} \mathrm{C}$ in an oven for 12 hours, thereafter cooled to room temperature in a desiccator.

\subsection{Description of the oxidation reactor}

The reactor was batch with respect to liquid and continuous with respect to the gas; it is shown schematically in Figure 1. The reactor set-up consists of a glass-lined $150 \mathrm{~mL}$ stainless steel autoclave (HEL Ltd, UK) rated to 100 bar and $250^{\circ} \mathrm{C}$. Heating was provided by placing the autoclave on a hot plate with aluminium reactor jacket to support the vessel and improve heat transfer. The reactor was also equipped with a pressure gauge, an IKA ETS-D5 temperature probe (IKA-Werke $\mathrm{GmbH}$, Germany) with an accuracy of $\pm 0.5^{\circ} \mathrm{C}$, a magnetic stirrer and liquid sampling tube for taking samples periodically from the reactor without perturbing the pressure in the system.

The outlet of the autoclave was connected to a $70 \mathrm{~cm}$ long stainless steel condenser, with 1,3propanediol/water mixture as coolant maintained at $-20^{\circ} \mathrm{C}$ by a Thermo Haake DC30/K20 cooling bath. Exiting gas from the condenser flowed through a back pressure regulator (BPR), which maintained a stable back pressure inside the reactor. The BPR is an RHPS series domeloaded pressure regulator (Proportion-Air Inc, USA), with a 0-90 barg calibrated range. The desired downstream pressure setpoint was achieved by supplying nitrogen at 7 bar to the BPR dome and adjusting the voltage command signal on a 0-10 VDC analogue potentiometer. The exit gas from the BPR goes through a three-way valve, which led to the vent or the gas chromatograph (GC) for analysis. The line was heated to prevent condensation of vapours. Gas feed to the reactor was controlled by a calibrated Sierra SmartTrak 100 mass flow controller (MFC; Sierra Instruments, USA) with an accuracy of $\pm 1 \%$. The experimental rig was placed inside a safety cabinet constructed with aluminium frames and $6 \mathrm{~mm}$ thick polycarbonate sheets 
and fitted with a fume extractor. To prevent the risk of explosive mixture forming in the reactor set-up, the oxygen content in the feed gas oxygen was kept below the limiting oxygen concentration (LOC), i.e. $10.2 \mathrm{vol} \%$ at $150^{\circ} \mathrm{C}$ and 30 bar $[45,46]$.

\subsection{Experimental procedure}

Three different types of experiments were performed: thermal oxidation of $n$-pentane, initiated oxidation of $n$-pentane with DTBP, and oxidation of $n$-pentane with DTBP initiator and boron compounds. A description of the procedure for oxidation in the presence of $s$-BuMB is given below; the steps are similar for other experiments with only minor modifications.

In a typical run, freshly activated molecular sieve, which had been heated in an oven at $260^{\circ} \mathrm{C}$ overnight and thereafter cooled to room temperature, was weighed into the reactor. The autoclave was connected to the condenser and air excluded from the apparatus with a flow of nitrogen. 1,4-difluorobenzene internal standard, DTBP radical initiator, purified $n$-pentane and $s$-BuMB were charged into the reactor using Hamilton gas-tight syringes with an accuracy of $\pm 1 \% .70 \mathrm{~mL}$ of $n$-pentane was used in all experiments, and the concentration of internal standard was kept the same as $13.947 \mu \mathrm{L}$ per $\mathrm{mL}$ of liquid charged. The amount of $s$-BuMB used was varied between 1.5 and 6.8 mol\% relative to $n$-pentane. Density of $s$-BuMB was taken as $0.985 \mathrm{~g} \mathrm{~mL}^{-1}$ at $20^{\circ} \mathrm{C}$ [47].

The desired back pressure was set by applying the appropriate voltage on the potentiometer (e.g. $3.33 \mathrm{~V}$ for $30 \mathrm{bar}$ ). The vent gas valve was shut and the reactor was pressurized with nitrogen using the maximum flow rate on the MFC, and the flow of was directed to the top of the reactor to minimise splashing of the liquid. 


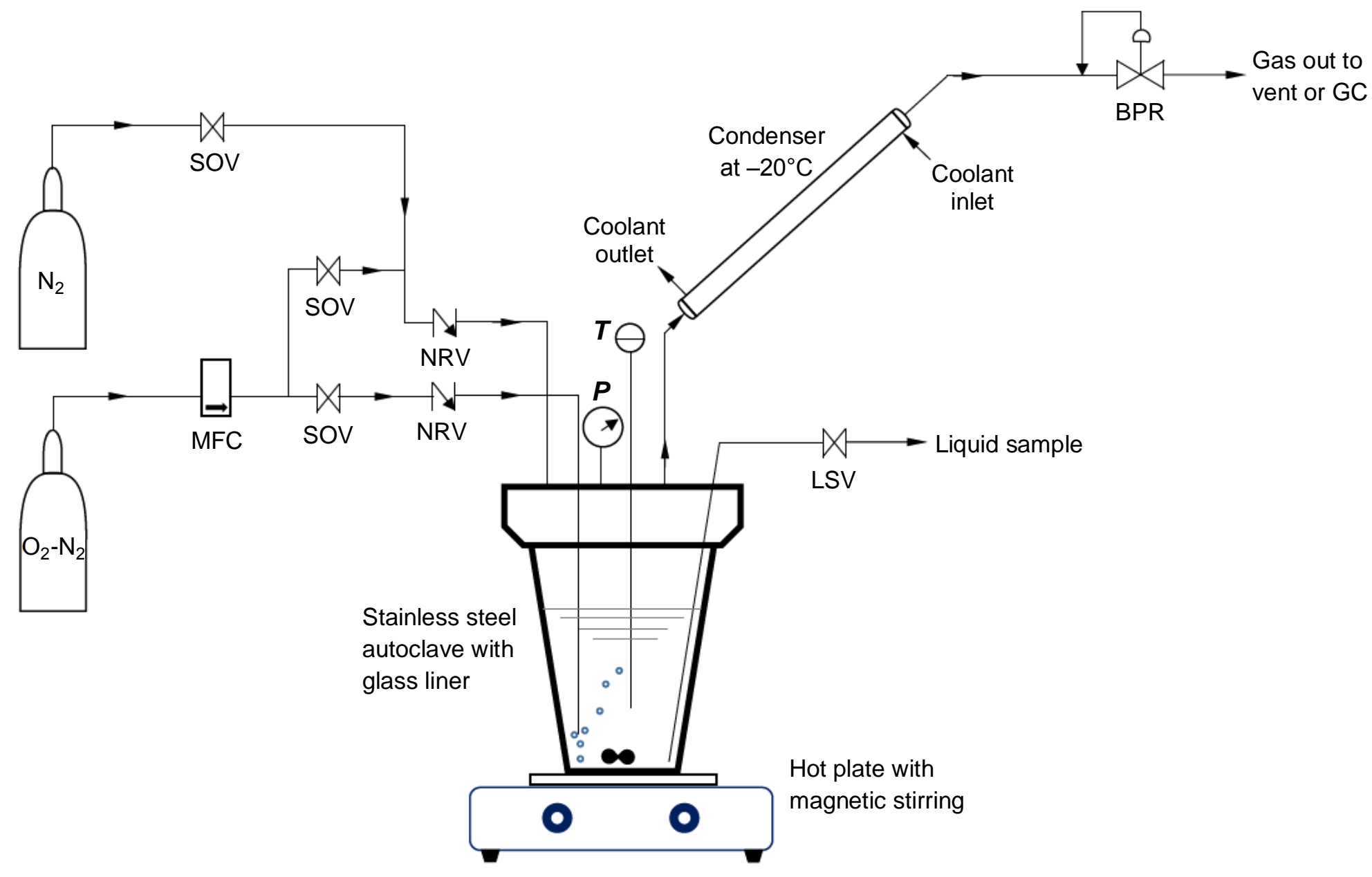

Figure 1. Schematic of the semi-batch reactor for oxidation of $n$-pentane.

MFC: Mass flow controller; NRV: non-return valve; BPR: back pressure regulator; SOV: shutoff valve; LSV: liquid sampling valve. 
Heating was turned on, and when the reactor reached the desired temperature, flow of the oxidising was started and directed through the gas sparger. Flow rate of the oxidising gas was maintained at $50 \mathrm{~mL} \mathrm{~min}^{-1}$ and the content of the reactor was stirred at $500 \mathrm{rpm}$ to ensure good mixing of gas and liquid phases. Duration of each experiment was 8 hours. Liquid samples were withdrawn periodically, first by purging the liquid sampling tube thereafter taking 500 $\mu \mathrm{L}$ of liquid for analysis. Simultaneously the exiting gas phase from the reactor was sent to the GC for analysis of gaseous products.

To recover alcohols from the liquid samples taking during oxidation with boron species, samples were treated with $1 \mathrm{~mL}$ deionised water at $50^{\circ} \mathrm{C}$ to hydrolyse borate esters. The mixture was shaken and left to stand for 20 minutes to ensure complete hydrolysis, followed by analyses of aliquots of the resulting aqueous and organic layers. The procedure described above was followed for the oxidation of $n$-pentane in the presence of TiPrB and boric oxide. During thermal and DTBP-initiated oxidations, boron compound was not used, and thus the liquid samples were analysed directly without hydrolysis.

\subsection{Analytical method and quantification of products}

Identification and quantitative analyses of oxidation products were undertaken on an Agilent 7890B GC integrated with a 5977B MSD and fitted with a CTC PAL autosampler, customised and supplied by JSB UK and Ireland Ltd. Gas phase was analysed on the GC, which was equipped with two thermal conductivity detectors (TCDs). Identities of the gas products were confirmed by injecting a standard gas mixture (Agilent RGA checkout sample P/N 5190-0519) containing $\mathrm{C}_{1}-\mathrm{C}_{6}$ hydrocarbons, hydrogen, $\mathrm{CO}, \mathrm{CO}_{2}$ and nitrogen. Helium was used as the carrier gas with a flow rate of $3 \mathrm{~mL} \mathrm{~min}^{-1}$. The GCMS side was equipped with a DB-WAX column (30 m long, $250 \mu \mathrm{m}$ diameter and $0.25 \mu \mathrm{m}$ film thickness) suitable for separating polar compounds. The identity of each liquid phase species was established using NIST MS library and subsequently confirmed by injecting authenticated analytical standards. Calibration and quantification of the main products were performed on an Agilent MassHunter ${ }^{\mathrm{TM}}$ quantitative analysis software based on the response factor of each analyte relative to the internal standard using specific mass ions for both species.

For the gas analysis, the inlet temperature and pressure were set to $250^{\circ} \mathrm{C}$ and $82.3 \mathrm{psi}$, respectively, while the detectors were maintained at $250^{\circ} \mathrm{C}$. Oven temperature was held at $35^{\circ} \mathrm{C}$ 
for $3 \mathrm{~min}$ then ramped at $10^{\circ} \mathrm{C} \mathrm{min}^{-1}$ to $90^{\circ} \mathrm{C}$ and held for $1.5 \mathrm{~min}$, and finally increased to $190^{\circ} \mathrm{C}$ at a rate of $10^{\circ} \mathrm{C} \mathrm{min}^{-1}$. Analysis time was 20 minutes with a further three minutes for post-run at $230^{\circ} \mathrm{C}$. Liquid products were analysed on the MS by taking $100 \mu \mathrm{L}$ aliquots and diluting to $1 \mathrm{~mL}$ in ethyl acetate. Inlet temperature was $300^{\circ} \mathrm{C}$ while the oven was programmed at $80^{\circ} \mathrm{C}$ for 1 minute, then ramped at $20^{\circ} \mathrm{C} \mathrm{min}^{-1}$ to $140^{\circ} \mathrm{C}$ and subsequently to $200^{\circ} \mathrm{C}$ at $50^{\circ} \mathrm{C}$ $\min ^{-1}$ and held for $1 \mathrm{~min}$. Split ratio was 100:1 and total analysis time was 6.2 minutes.

For experimental runs with boron compounds, both aqueous and organic phases were analysed using the same amount of internal standard, so that the total concentration of oxidation products is given by the sum of the amounts of the product in both phases, as written in Eq. (1). MS chromatogram of the aqueous phase showed no presence of 1,4-difluorobenzene, hence an amount of internal standard equivalent to that in the organic phase was added into each aqueous phase sample vials prior to analysis on the MS.

$$
C_{i}=C_{i, a q}+C_{i, o r g}
$$

Due to high volatility of $n$-pentane, accurate determination of the conversion of the hydrocarbon was significantly challenging. Thus, analysis of the reactor performance was based on product selectivity and yield, defined in Eqs. (2) and (3), respectively.

$$
\begin{gathered}
S_{s-\mathrm{PeOH}}=\frac{\text { mol of sec-pentanol }}{\sum \text { mol of products }} \times 100 \% \\
Y_{i}=\frac{\text { mol of product } i}{\text { initial mol of } n \text {-pentane }} \times 100 \%
\end{gathered}
$$

\section{Results and discussion}

\subsection{Product distribution}

The main liquid products of pentane oxidation identified by MS are alcohols (2- and 3pentanols), ketones (2- and 3-pentanones), carboxylic acids (mainly $\mathrm{C}_{2}$ and $\mathrm{C}_{3}$, with some $\mathrm{C}_{4}$ and $\mathrm{C}_{5}$ ) and esters (2-pentyl acetate and 2-pentyl propanoate). An example chromatogram is shown in Figure S1 (Supporting Information). 2- and 3-pentanones overlapped each other at the same retention time, hence they could not be determined separately. Negligible amount of formic acid was formed while 1-pentanol was not detected at all, the latter confirming that $n$ pentane is predominantly oxidised at the methylene groups in the alkane chain. Chromatographic analysis of the gas evolved indicates that $\mathrm{CO}_{2}$, resulting from total oxidation of $n$-pentane, is the main gaseous product while $\mathrm{CO}$ and lower molecular weight hydrocarbons 
$286\left(\mathrm{C}_{1}\right.$ to $\mathrm{C}_{4}$ alkanes $)$ were also produced, although in much smaller concentrations. 287 Acetaldehyde, a low boiling aldehyde, was also detected in the gas phase. Overall, the yield of gaseous products was negligible.

The formation of carboxylic acids as well as small-chain alkanes provide an indication of significant $\mathrm{C}-\mathrm{C}$ cleavage reactions, which involves $\beta$-scission of sec-pentoxy radicals mainly into acetaldehyde, propionaldehyde and free radicals. The aldehydes readily oxidise to acids while the free radicals abstract hydrogen from $n$-pentane to give the lower alkanes observed in the reaction mixture [48-50].

295

\subsection{Thermal and peroxide-initiated oxidation}

297 The variation of product yield and sec-pentanol selectivity with time during the thermal uninitiated oxidation of $n$-pentane at $150^{\circ} \mathrm{C}$ with $10 \mathrm{vol} \%$ oxygen in the feed gas and $30 \mathrm{bar}$ total pressure are shown in Figure 2(a). In the early stages of oxidation, the yield of alcohols, ketones and acids are similar: $0.19 \%, 0.23 \%$ and $0.26 \%$, respectively, after 1 hour. However, as the reaction progresses the formation of pentanones and acids rapidly increased compared to sec-pentanols. After 8 hours of reaction, sec-pentanol yield is $0.56 \%$ while the yields of pentanones and acids are $10.5 \%$ and $13.9 \%$, respectively. Selectivity to sec-pentanols reached a maximum of $27.6 \%$ after 1 hour, after which it declines progressively to $2.2 \%$ after 8 hours of reaction. This observation is due to the intermediate nature of the alcohols during the oxidation of alkanes, hence their subsequent non-selective oxidation to by-products such as ketones and acids. Furthermore, the ratio of 2-pentanol to 3-pentanol formed is roughly 2:1, consistent with the number of secondary $\mathrm{C}-\mathrm{H}$ bonds at the 2-and 3-position as well as the preferential oxidative attack on the methylene groups near the ends of an alkane chain [50,51]. The yield of pentanones also appear to decreases after about 6 hours of reaction, which may be due to their consecutive oxidation to acids. 

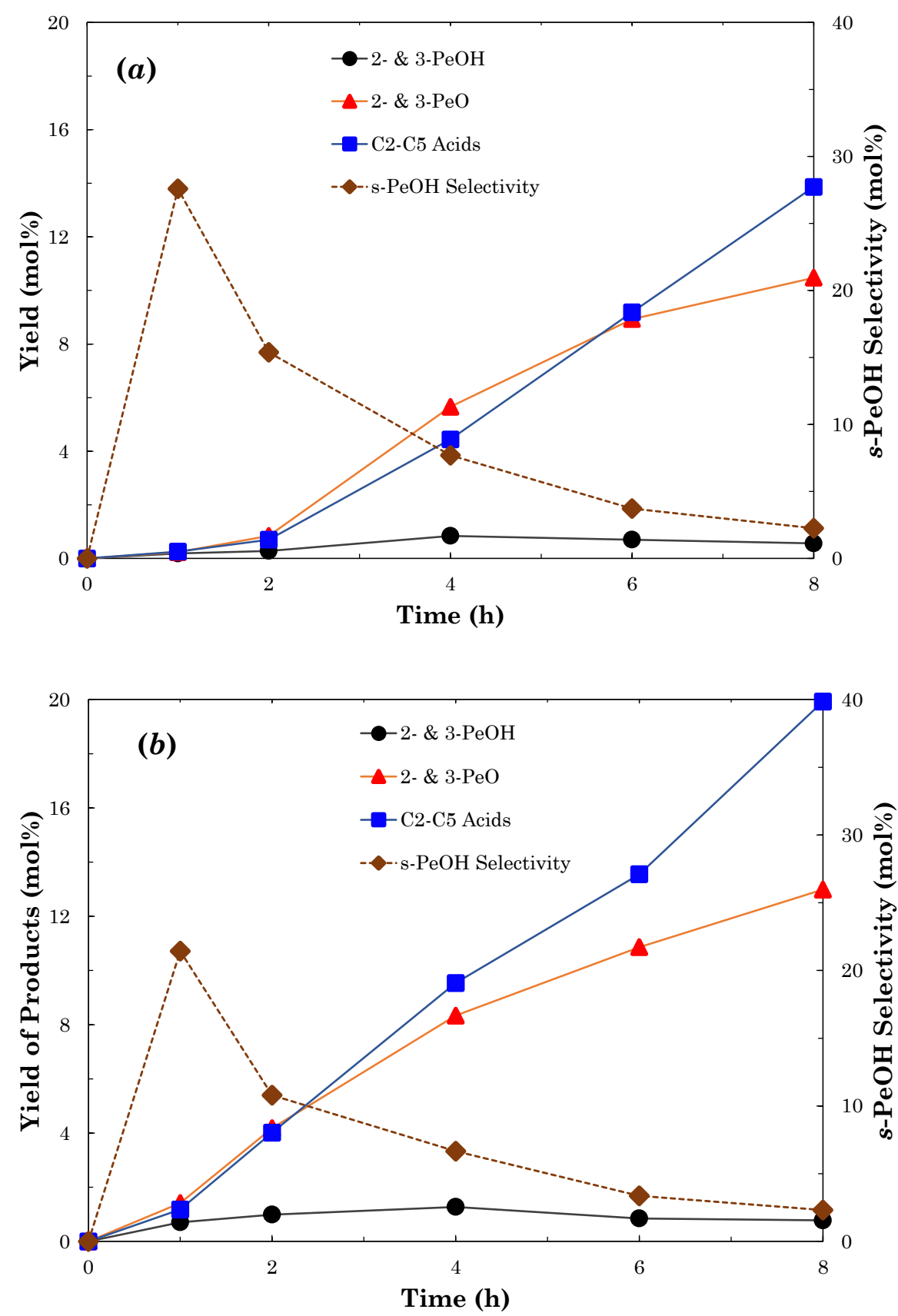

Figure 2. Thermal and DTBP-initiated oxidations of $n$-pentane. (a) Thermal oxidation $(b)$ Initiated oxidation with 1 vol\% DTBP. $T: 130^{\circ} \mathrm{C}, P: 30$ bar, $y_{\mathrm{O}_{2}, i n}: 0.1$.

313 The influence of radical initiator on the oxidation was investigated with 1 vol\% DTBP under 314 the same conditions as the thermal oxidation. Figure $2(b)$ shows that the yield and selectivity profiles are similar to those in Figure 2(a). The yield of sec-pentanols increased at first reaching

$3161.27 \%$ after four hours and declines thereafter, pentanone formation appeared to slow down 317 while yield of acids continue to increase over the course of the reaction. After one hour, the yield of alcohols, ketones and acids are $0.71 \%, 1.42 \%$ and $1.18 \%$, respectively, which 
increased to $0.78 \%, 13 \%$ and $19.93 \%$ after 8 hours. In terms of selectivity, Figure $2(b)$ shows that the optimum sec-pentanol formation occurred after one hour, as indicated by the selectivity of $21.4 \%$, which reduces to $2.3 \%$ after 8 hours.

Figure 3 compares the cumulative yield of the products for thermal and DTBP-initiated oxidations of $n$-pentane over the course of four hours. The presence of DTBP significantly increased the initial rate of the oxidation of $n$-pentane, and hence yield, whereas thermal oxidation without an initiator was quite slow in the early stages. The action of DTBP on the oxidation process is connected with a sharp reduction of the induction period due to an increase in the rate of hydrogen abstraction from $n$-pentane and subsequent oxygen uptake. These results confirm the fact that oxidation of $n$-pentane in the presence of an initiator can result in higher yield of products, with only a slightly lower sec-pentanol selectivity.

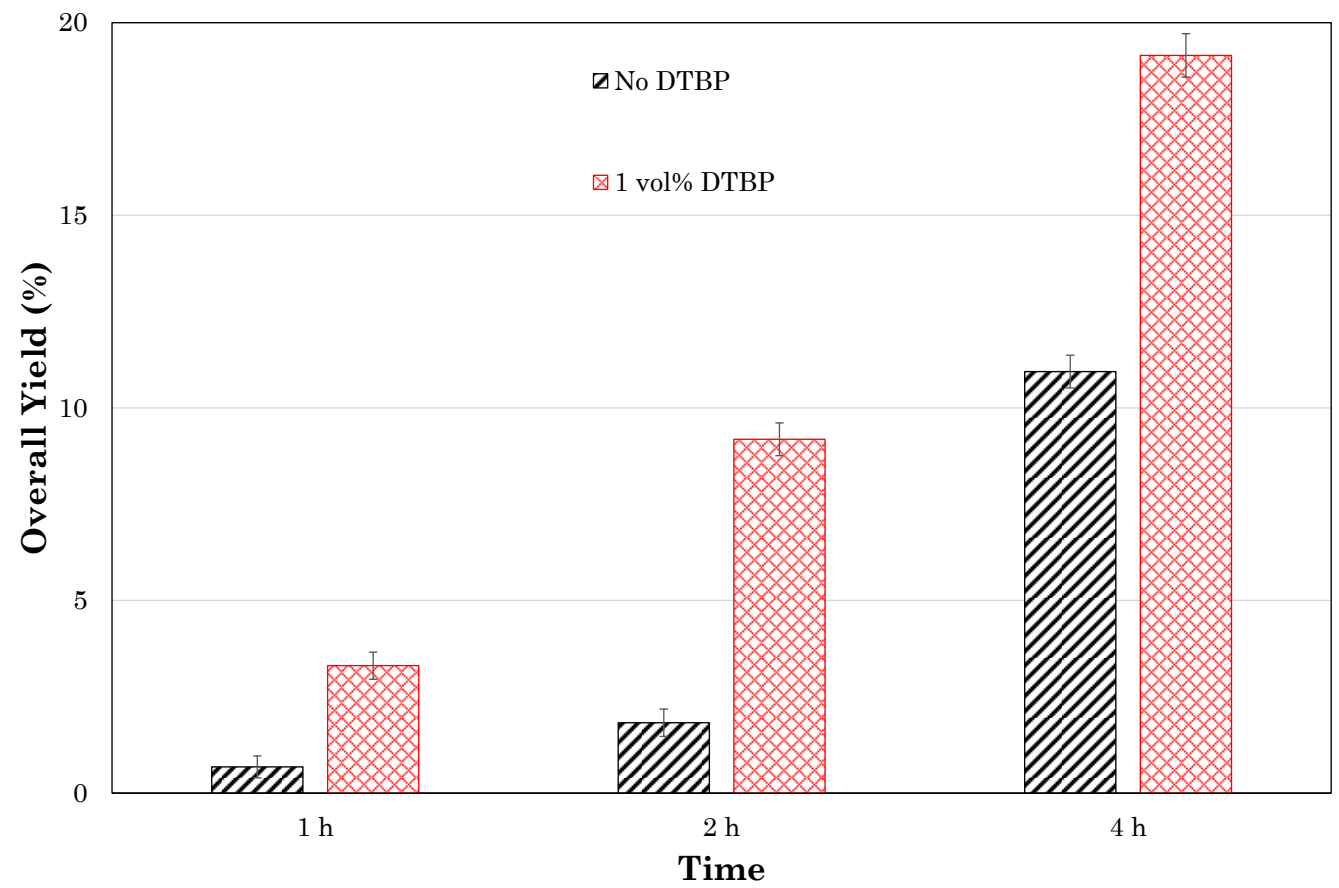

Figure 3. Effect of initiator on $n$-pentane oxidation. $T: 150^{\circ} \mathrm{C}, P: 30 \mathrm{bar}, y_{\mathrm{O}_{2}, \text { in }}: 0.1$.

332 Furthermore, oxidation of $n$-pentane at $130^{\circ} \mathrm{C}$ initiated with different initial concentrations of 333 DTBP was undertaken, the results of which are shown in Figure 4. First, for the same DTBP concentration of $1 \mathrm{vol} \%$, lowering the reaction temperature to $130^{\circ} \mathrm{C}$ led to a considerable reduction in ketone and acid formation compared to the oxidation at $150^{\circ} \mathrm{C}$ shown in Figure 2(b). For oxidation with 1 vol\% DTBP at $130^{\circ} \mathrm{C}$, the respective yield of sec-pentanols, pentanones and acids are $0.12 \%, 0.09 \%$ and $0.42 \%$ after one hour, which increased to $0.59 \%$, $1.87 \%$ and $1.61 \%$, respectively, after 8 hours. 


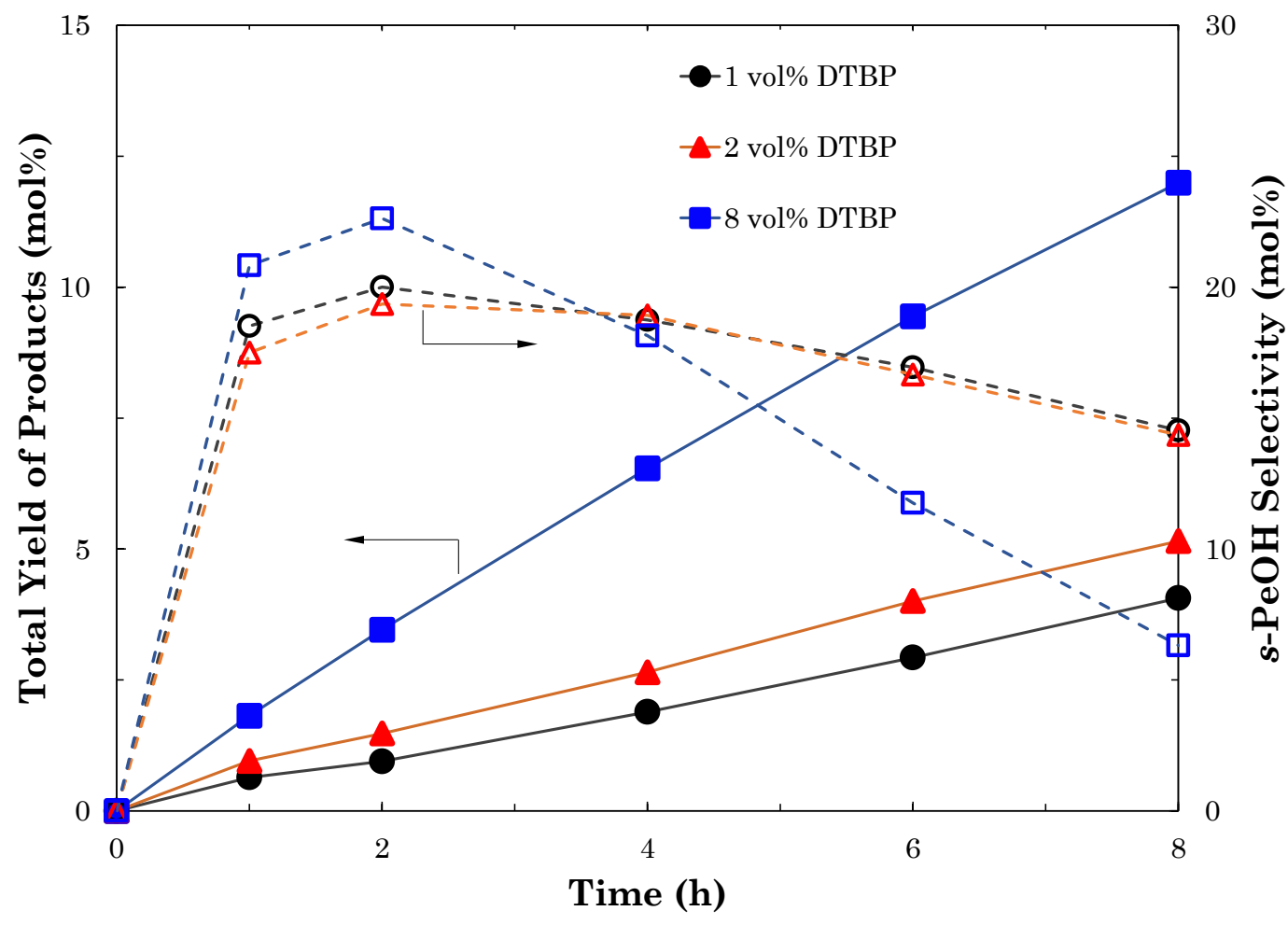

Figure 4. DTBP-initiated oxidation of $n$-pentane at $130^{\circ} \mathrm{C}, P: 25$ bar, $y_{\mathrm{O}_{2}, \text { in }}: 0.1$.

340 It can also be seen from Figure 4 that the maximum sec-pentanol selectivity of $20 \%$ is achieved after two hours, which declines to $14.5 \%$ over the duration of the oxidation. Thus, for the same level of the initiator concentration, a reduction in temperature favours higher selectivity to alcohols, especially at longer reaction times. It is evident that further increase in the concentration of DTBP improves the rate of oxidation, hence yield. However, between 1 and 2 vol\% DTBP, there is only a marginal change in selectivity to sec-pentanol. When the amount of DTBP used for the oxidation is raised to 8 vol\%, the yield markedly increases, as does the selectivity to alcohol in the early stages. However, the decrease in the alcohol selectivity is more pronounced than for 1 and 2 vol\% DTBP, which may be due to increase in the rates of secondary reactions. These observations indicate that higher levels of initiator increases the concentration of chain-initiating radicals, giving higher conversion of $n$-pentane, and thus yield of oxygenated products.

\subsection{Effect of boron concentration on the oxidation}


The influence of boron on the oxidation process was investigated over a range of operating conditions. First, DTBP-initiated oxidation runs at $150^{\circ} \mathrm{C}$ in Figure $2(b)$ and $130^{\circ} \mathrm{C}$ in Figure 4 , both with 10 vol\% oxygen in the feed gas, were repeated with different concentrations of sec-butyl metaborate. Figure 5 shows the selectivity and yield profiles.

It can be seen from Figure 5(a) that in the early stages of the reaction, up to one hour, the initiated oxidations of $n$-pentane in the presence of the metaborate ester proceeds almost as efficiently as with DTBP only. This indicates that the reaction mechanism remains unchanged from the free-radical mechanism as with the initiator alone [17,52]. Beyond the initial period, however, the oxidation with the boron species progressively gives lower overall yield of the products, with $18.9 \%$ after 8 hours for the run with $1.5 \mathrm{~mol} \% s$-BuMB initiated by DTBP compared to $33.2 \%$ for the oxidation with DTBP only. Doubling the concentration of $s$-BuMB further reduces the total yield to $16.5 \%$ after 8 hours. Furthermore, it can be seen that the presence of boron significantly improves sec-pentanol selectivity, the optimum values of which are attained after two hours. With $1.5 \mathrm{~mol} \% \mathrm{~s}$-BuMB, maximum selectivity is $37.9 \%$ at $3.24 \%$ yield compared to $21.4 \%$ at $3.31 \%$ yield for oxidation with DTBP only. Doubling the concentration of boron to $3 \mathrm{~mol} \%$ further improves sec-pentanol selectivity, giving a maximum of $43.5 \%$ at $3.16 \%$ yield after two hours.

Figure $5(b)$ shows the results of oxidation runs at $130^{\circ} \mathrm{C}$ with $3 \mathrm{~mol} \% s$-BuMB. The run with 8 vol\% DTBP and no boron was presented earlier in Figure 2, where the optimum sec-pentanol selectivity was found to be $22.6 \%$ after two hours with a corresponding total yield of $3.46 \%$. In comparison, when this experiment was repeated with $3 \mathrm{~mol} \% s$-BuMB in the reaction medium, Figure 5(b) shows that the rate of oxidation was inhibited, leading to lower yield compared to the run without boron. However, selectivity to sec-pentanols is significantly improved due to the presence of the alkyl metaborate. When the concentration of DTBP was increased to $10 \mathrm{vol} \%$ while maintaining the concentration of the metaborate ester at $3 \mathrm{~mol} \%$, it can be seen that the rate of oxidation of $n$-pentane increased to give product yields similar to that achieved during oxidation without the boron compound. sec-Pentanol selectivity is also still better than with DTBP only, however, the values are lower compared to the run with 8 vol\% DTBP and 3 mol\% s-BuMB. 

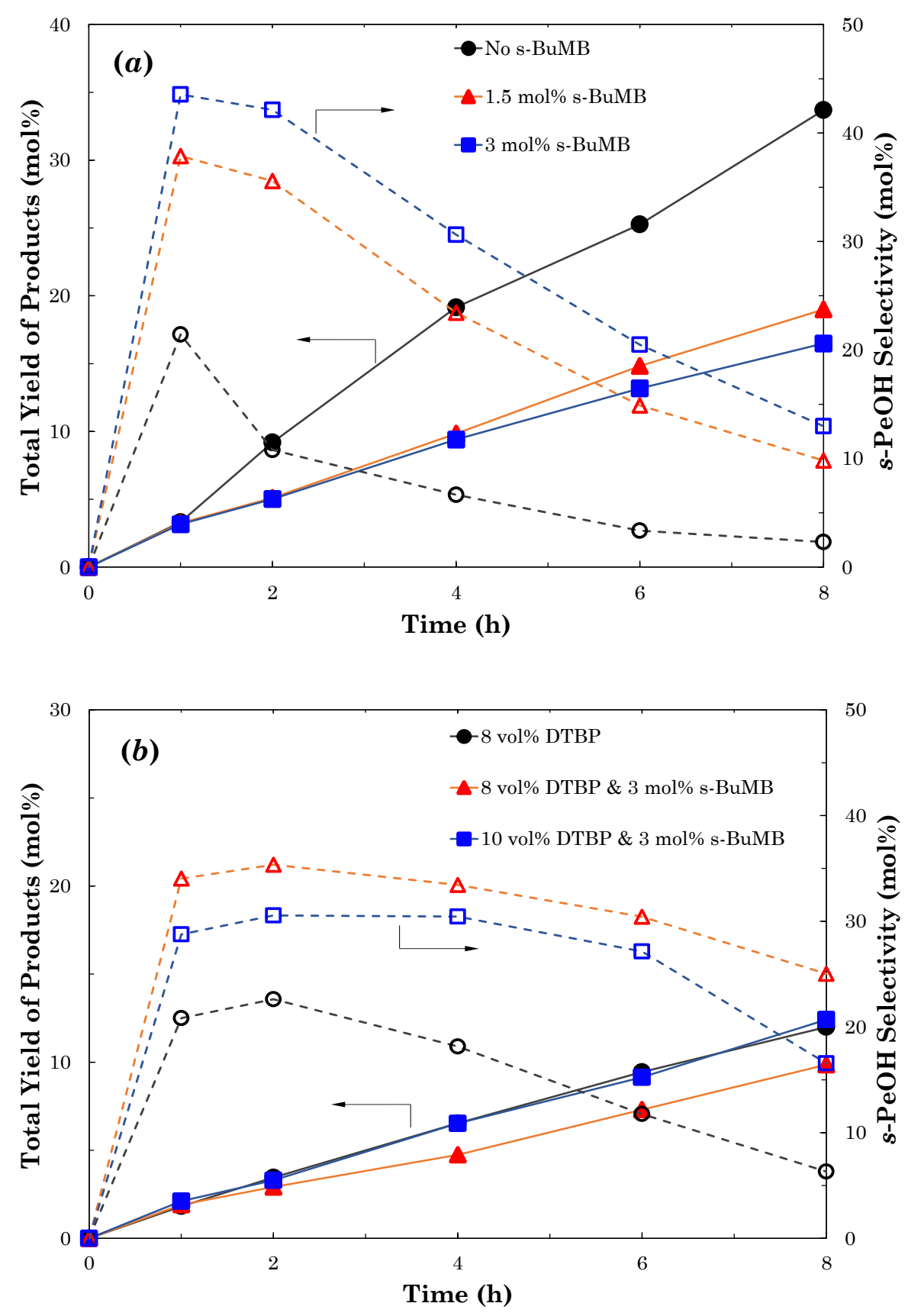

Figure 5. Effect of sec-butyl metaborate on the oxidation of $n$-pentane. (a) $T: 150^{\circ} \mathrm{C}, P: 30$ bar, $y_{\mathrm{O}_{2}, \text { in }}: 0.1, C_{\mathrm{DTBP}}: 1 \mathrm{vol} \%, 10 \mathrm{~g} \mathrm{AO}$ sieve. (b) $T: 130^{\circ} \mathrm{C}, P: 25 \mathrm{bar}, y_{\mathrm{O}_{2}, \text { in }}: 0.1,12 \mathrm{~g} \mathrm{AO}$ sieve. Note: AO denotes "ACROS Organics" sieve.

386 These results show the feasibility of achieving an improved alcohol selectivity in the presence of boron under conditions that give similar conversion as the oxidation without boron. In other words, it is possible to achieve improved selectivity without significant trade-off in conversion, thus maximising the yield. 
391

392

393

394

395

396

397

398

399

Furthermore, the effect of varying boron concentrations on the oxidation was investigated with 5 vol\% oxygen in the feed gas. Table 2 summarises the optimum selectivity, the corresponding product yield and $\mathrm{ROH} / \mathrm{R}$ 'O ratio after two hours of reaction. The results again clearly confirm that while the rate of oxidation is fairly similar in the early stages with and without boron, the presence of the metaborate ester alters the product distribution, directing the oxidation towards increased alcohol production.

Table 2. Experimental results at $2 \mathrm{~h}$ for oxidation with varying $s$-BuMB concentration. T: $150^{\circ} \mathrm{C}, P: 30$ bar, $y_{\mathrm{O}_{2}, \text { in }}: 0.05, C_{D T B P}: 10$ vol\%, $15 \mathrm{~g}$ UOP sieve.

\begin{tabular}{lcccc}
\hline & DTBP & \multicolumn{3}{c}{ Oxidation with DTBP and $s$-BuMB } \\
\cline { 3 - 5 } & only & 3.7 mol\% & 5.4 mol\% & 6.8 mol\% \\
& & $s$-BuMB & $s$-BuMB & $s$-BuMB \\
\hline$s$-PeOH selectivity (\%) & 33.5 & 46.4 & 49.4 & 54.7 \\
Overall product yield (\%) & 5.45 & 4.65 & 4.59 & 4.48 \\
$s$-PeOH:PeO ratio & 1.06 & 1.93 & 2.17 & 2.56 \\
\hline
\end{tabular}

400

401

4.4. Influence offeed gas composition and total pressure

402

The dependence of reactor performance on varying oxygen concentration was investigated with

403 oxidising gas mixtures containing between 5 and 10 vol\% oxygen. It is evident from Figure 6 that with increasing oxygen content in the feed gas, the rate of reaction, hence product yield, increases with reaction time. However, higher oxygen concentration in the feed gas has a detrimental effect on the formation of sec-pentanols, leading to lower selectivity. In addition, as the oxygen content increases, the optimum reaction time at which the maximum selectivity is attained shifts slightly to the left. Thus, for 5 and 10 vol\% oxygen in nitrogen, maximum selectivity of 49.1 and $43.8 \%$ are attained at around two and one hours, respectively. 


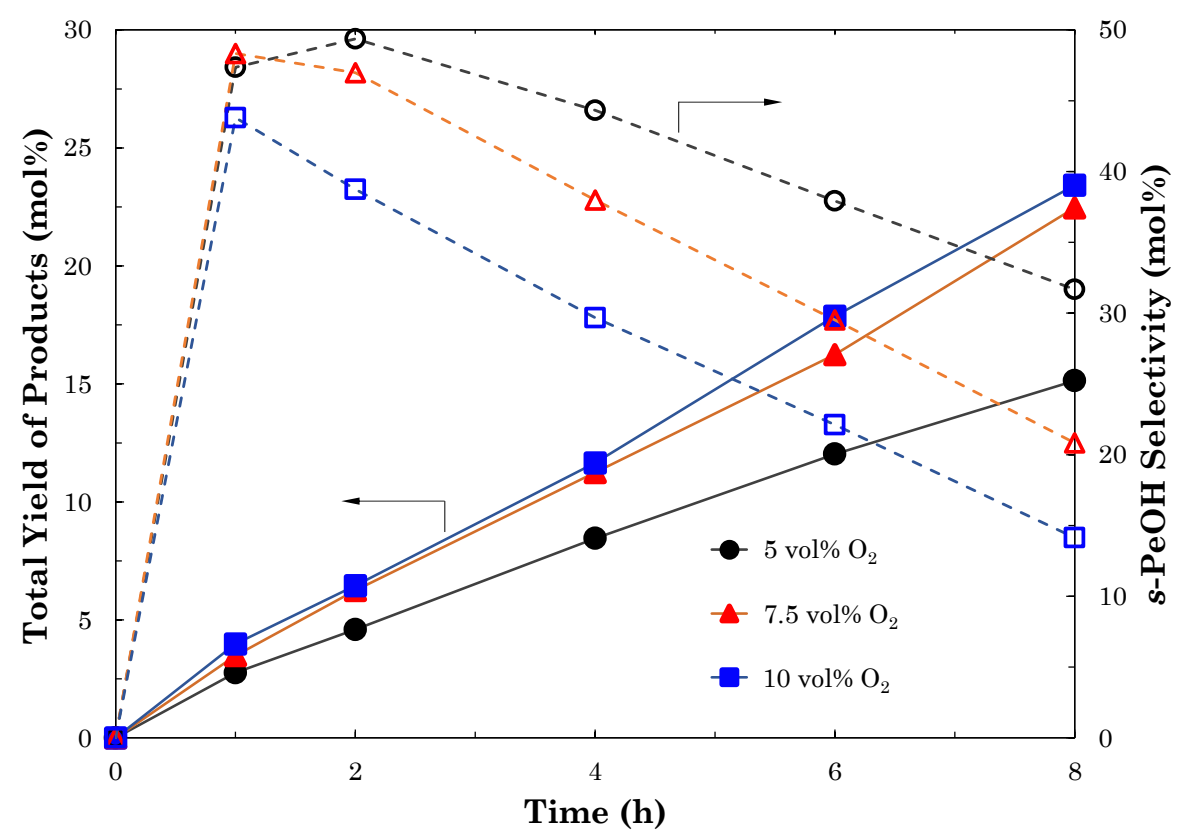

Figure 6. Effect of oxygen concentration on selectivity and yield. T: $150^{\circ} \mathrm{C}, P: 30$ bar, $C_{s-\mathrm{BuMB}}: 3.7 \mathrm{~mol} \%, C_{D T B P}: 10 \mathrm{vol} \%, 15 \mathrm{~g} \mathrm{UOP}$ sieve.

411 The effect of oxygen content on reaction selectivity and yield was further investigated by 412 varying the total reactor pressure with 5 vol\% oxygen in the feed gas. The results obtained are shown in Figure 7. Over the range investigated, the reaction profiles show that the effect of total pressure on both the cumulative yield of oxidation products as well as sec-pentanol selectivity is small but not negligible. There is a slight increase in conversion, and consequently yield, with a marginal decrease in alcohol selectivity as the total pressure increased. For reactor pressure of 20 bar after two hours of oxidation, the overall yield of the oxygenated products was $4.18 \%$ while the corresponding sec-pentanol selectivity was $51.4 \%$, compared to $4.62 \%$ yield and selectivity of $49.1 \%$ in the case of 30 bar reactor pressure after the same duration of reaction.

From Figures 6 and 7 it can be reasoned that as the partial pressure of oxygen in the gas phase increases, the interfacial concentration of oxygen increases leading to higher availability of dissolved oxygen in the liquid phase. This consequently increases the rate of oxidation of $n$ pentane and the product yield. On the other hand, higher dissolved oxygen concentration increases the rate of consecutive oxidation of $\mathrm{sec}$-pentanols into pentanones and acids as well as total combustion side products such as $\mathrm{CO}_{2}$, thus lowering selectivity. In addition, the higher rate of oxidation due to increased oxygen concentration presumably increases the water 
formed, which rapidly saturates the molecular sieve adsorbent. The free moisture can cause premature hydrolysis of the protected sec-pentanols, thereby exposing them to further oxidative attack, and thus lower selectivity.

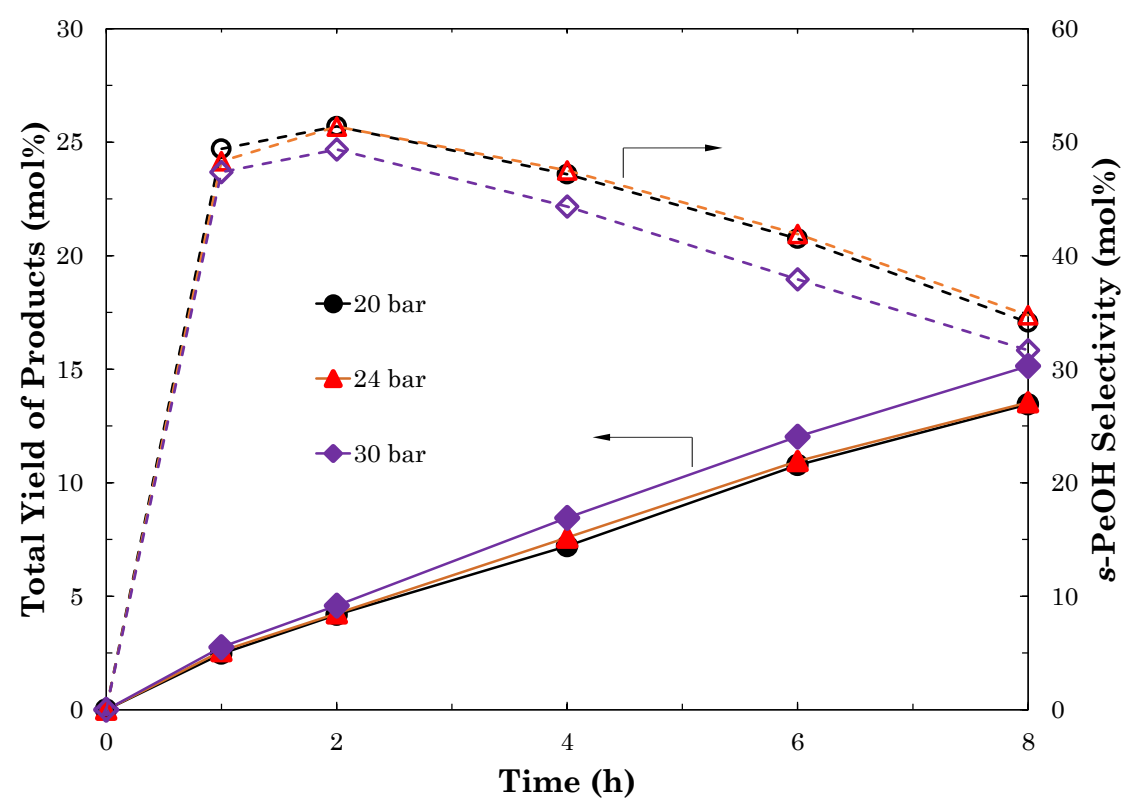

Figure 7. Influence of total pressure on reactor performance. $T: 150^{\circ} \mathrm{C}, y_{\mathrm{O}_{2}, \text { in }}: 0.05, C_{S-B u M B}$ : $5.4 \mathrm{~mol} \%, C_{\text {DTBP }}: 10$ vol\%, $15 \mathrm{~g}$ UOP sieve.

432

433

434

435

436

437

438

439

440

441

442

443

444

445

446

447

\subsection{Effect of reaction temperature}

Over the range of 130 to $150^{\circ} \mathrm{C}$, the influence of temperature on the on the rate of oxidation and product distribution was studied in the presence of boron. The selectivity and yield profiles are shown in Figure 8. The results show that the rate of $n$-pentane oxidation increases with temperature as indicated by the higher yield of products. As temperature increases, the rate of thermal homolysis of the radical initiator also increases, leading to higher conversion of the hydrocarbon. Selectivity to sec-pentanols also improves significantly with the reaction temperature, which may be attributed to two effects. First, higher temperature may be responsible for increasing the rate of heterolytic decomposition of the boron-hydroperoxide intermediate complex to favour sec-pentanol formation. Furthermore, the trans-esterification of sec-pentanols with sec-butyl metaborate is a slightly endothermic reaction $\left(\Delta H_{r}^{0}=\right.$ $+5.43 \mathrm{~kJ} \mathrm{~mol}^{-1}$ ), hence as temperature increases the equilibrium shifts towards the right to give higher yield of sec-pentyl borate esters, thus sec-pentanols upon hydrolysis. Other published literatures on the oxidation of hydrocarbons in the presence boron compounds have also reported increased alcohol selectivity with an increase in the reaction temperature [17]. 


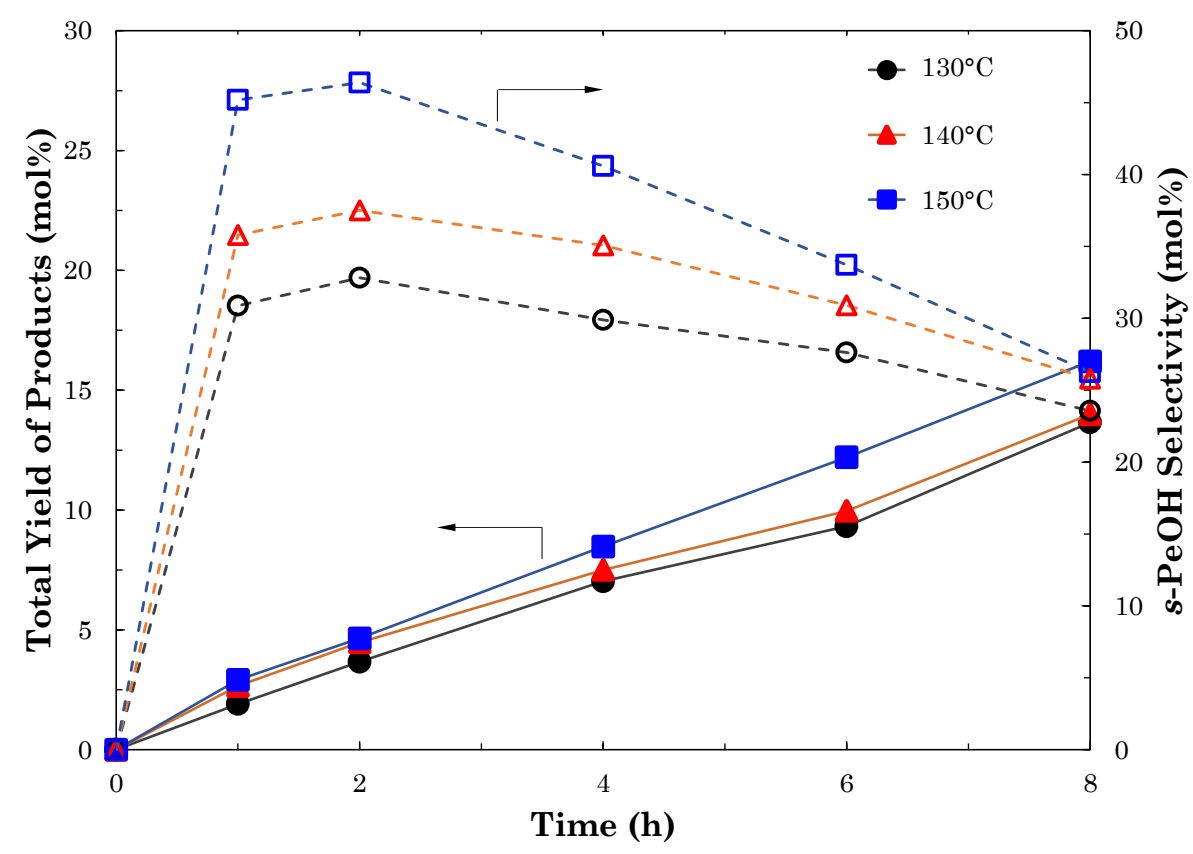

Figure 8. Dependence of yield and selectivity on reaction temperature. $P: 30$ bar, $y_{\mathrm{O}_{2} \text {,in }}: 0.05$, $C_{s-\mathrm{BuMB}}: 3.7 \mathrm{~mol} \%, C_{\mathrm{DTBP}}: 10 \mathrm{vol} \%, 15 \mathrm{~g} \mathrm{AO}$ sieve.

\subsection{Influence of boron species on the oxidation}

450 It is known that different types of boron compounds exert varying levels of influence on the process in terms of alcohol selectivity and inhibition of the oxidation. For example, boric oxide, $\mathrm{B}_{2} \mathrm{O}_{3}$, has been found to be more reactive than orthoboric acid, $\mathrm{B}(\mathrm{OH})_{3}$, and trialkyl orthoborates, $\mathrm{B}(\mathrm{OR})_{3}$, for the decomposition of hydroperoxides. This structure-reactivity effect is due to differences in the Lewis acidity, and hence the ability of different boron to coordinate with unpaired electrons on the oxygen atom of hydroperoxides [53-55].

457 The oxidation of $n$-pentane was investigated with three different boron compounds of varying 458 Lewis acidity and physical forms: sec-butyl metaborate ( $s$-BuMB), triisopropyl borate (TiPrB) and boric oxide. The experimental results obtained when the oxidation was carried with similar molar concentration of the boron reagents are presented in Figure 9. These are compared with oxidation without the boron compounds. 

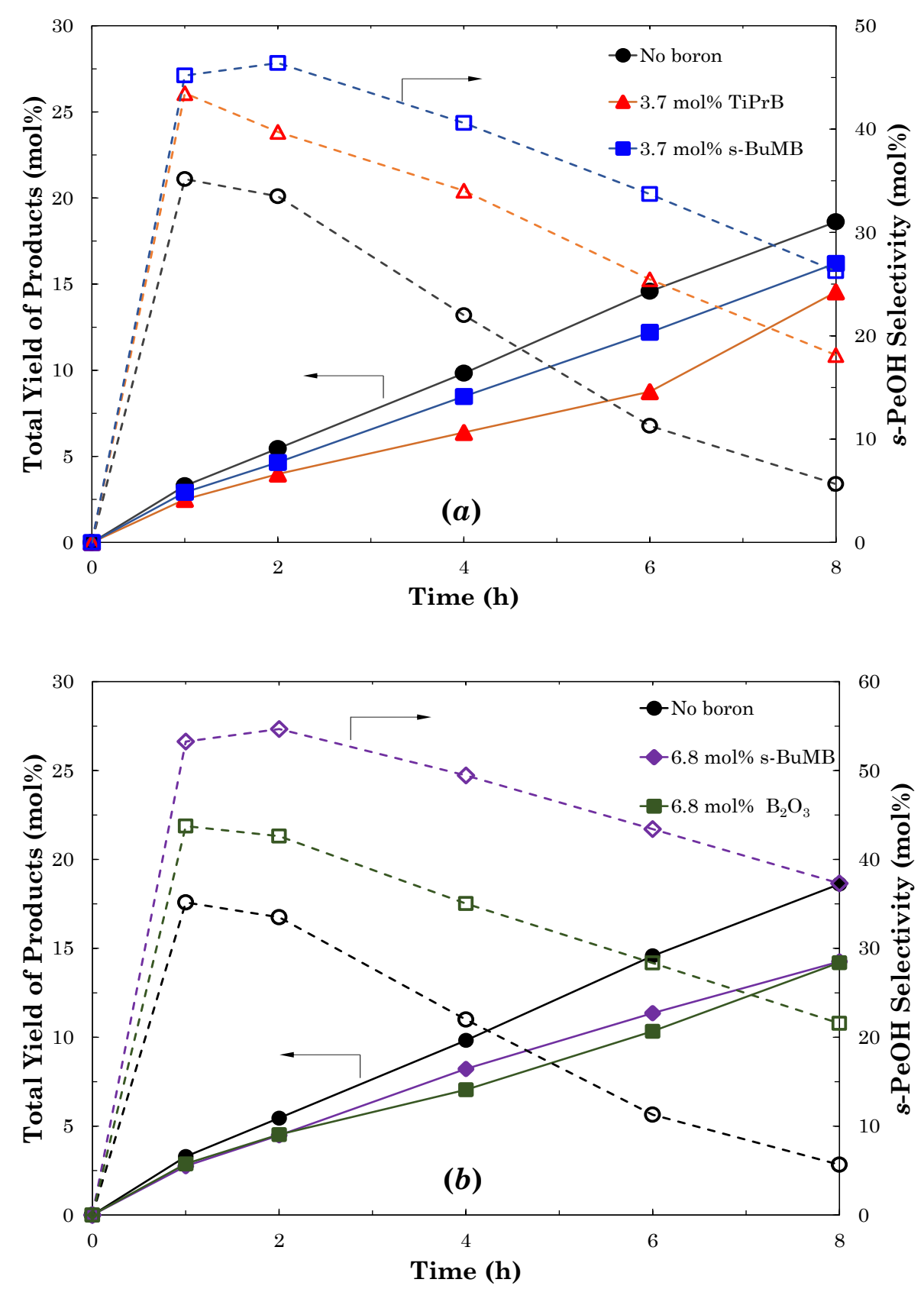

Figure 9. Effect of boron species on product selectivity and yield. $T: 150^{\circ} \mathrm{C}, P: 30 \mathrm{bar}$, $y_{\mathrm{O}_{2}, \text { in }}: 0.05, C_{\mathrm{DTBP}}: 10$ vol\%, $15 \mathrm{~g}$ UOP sieve.

463 From Figures 9(a) and (b), it can be seen that the selectivity and yield profiles for both $\operatorname{T} i \operatorname{PrB}$ 464 and boric oxide are similar to that of $s$-BuMB, and all three boron compounds improve alcohol 465 selectivity compared to the oxidation with DTBP only. However, $s$-BuMB gives higher product 466 yield as well as selectivity to sec-pentanols than $\mathrm{TiPrB}$ as shown in Figure $9(a)$. The 467 orthoborate appears to inhibit the oxidation far more than the metaborate ester, especially at later stages of the reaction. Furthermore, from Figure 9(b), the yield of oxidation products are 
similar for both boron compounds, however, sec-pentanol selectivity is significantly higher for $s$-BuMB compared to boric oxide. Based on these findings, it may be suggested that an alkyl metaborate is far more effective for directing the oxidation of $n$-pentane towards the formation sec-pentanols compared to an orthoborate and boric oxide. These observations agree with the findings of Itskovich et al. [22], McMahon and Chafetz [56] and Illingworth [57], who investigated the oxidation of alkanes and cycloalkanes with various types of boron compounds, and reported that alkyl metaborates give better selectivity and less inhibition of the oxidation than trialkyl orthoborates and boric acid. The fact that $s$-BuMB gives better selectivity than the same concentrations of $\mathrm{T} i \operatorname{PrB}$ and boric oxide can be explained by the higher Lewis acidity of alkyl metaborates compared to alkyl orthoborates and boric oxide $[52,58,59]$.

\subsection{Dependence of alcohol-to-ketone ratio on reaction conditions}

Alcohol-to-ketone ratio is an important parameter that defines the effectiveness of a boron compound for directing the oxidation towards the formation of alcohols. For the oxidation of $n$-pentane at $150^{\circ} \mathrm{C}$ with 5 vol\% oxygen in the feed gas and three different concentrations of sec-butyl metaborate as well as without the boron species, the results are presented in Figure 10. It can be seen that, in general, the trends follow closely that of sec-pentanol selectivity: maximum alcohol-to-ketone ratio is achieved in the first hour of the reaction, regardless of the presence of boron, which thereafter decreases progressively with time. This observation is due to over-oxidation of the alcohols to pentanones with increasing conversion. Furthermore, oxidation with sec-butyl metaborate clearly gave higher yields of $s e c$-pentanols relative to pentanones compared to oxidation carried out without added boron, and the value increases with increasing boron concentration. For the oxidation of $n$-pentane with $3.7 \mathrm{~mol} \% s$-BuMB, the optimum alcohol-to-ketone ratio is 2.14 compared to 1.41 achieved for the oxidation in the absence of boron. The yields of sec-pentanols relative to pentanones increased further to 2.37 and 2.88 for $5.4 \mathrm{~mol} \%$ and $6.8 \mathrm{~mol} \%$ sec-butyl metaborate, respectively. The increase in alcohol production with an increase in boron concentration is due to an increase in the rate of heterolytic decomposition of sec-pentyl hydroperoxide to form sec-pentanols, as well as the increase in the rate of protective transesterification of the alcohols formed. 


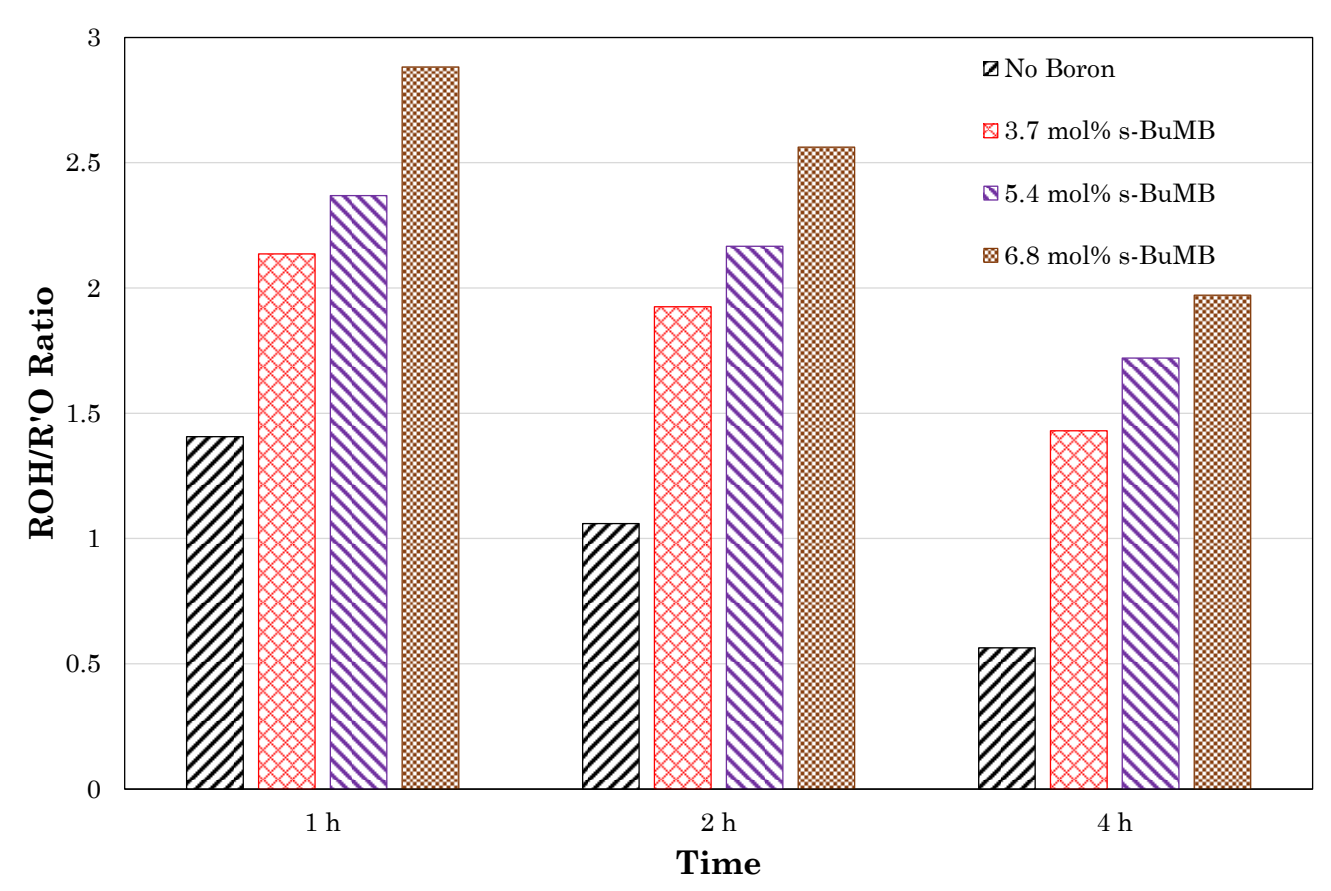

Figure 10. Influence of boron concentration on $\mathrm{ROH} / \mathrm{R}^{\prime} \mathrm{O}$ ratio. $T: 150^{\circ} \mathrm{C}, P: 30$ bar, $y_{\mathrm{O}_{2}, \text { in }}$ : $0.05, C_{\text {DTBP }}: 10$ vol\%, 15 g UOP sieve.

498

499 The dependence of the alcohol-to-ketone ratio on the operating temperature is presented in 500 Figure 11. Similar to the trends discussed above, Figure 11 shows that the yield of sec501 pentanols relative to pentanones reached a maximum in one hour and subsequently decreased 502 with reaction time. For oxidation of $n$-pentane in the absence of boron, increasing reaction 503 temperature from 130 to $150^{\circ} \mathrm{C}$ resulted in a decrease in in the alcohol-to-ketone ratio (see 504 Figures 2(b) and 5), whereas in the presence of boron, the ratio increased with temperature as 505 shown in Figure 11. The increase in pentanol-to-pentanone ratio with temperature in the 506 presence of boron may be due to an increase in the rate of heterolytic decomposition of sec507 pentyl hydroperoxides into alcohols at the expense of ketones. 


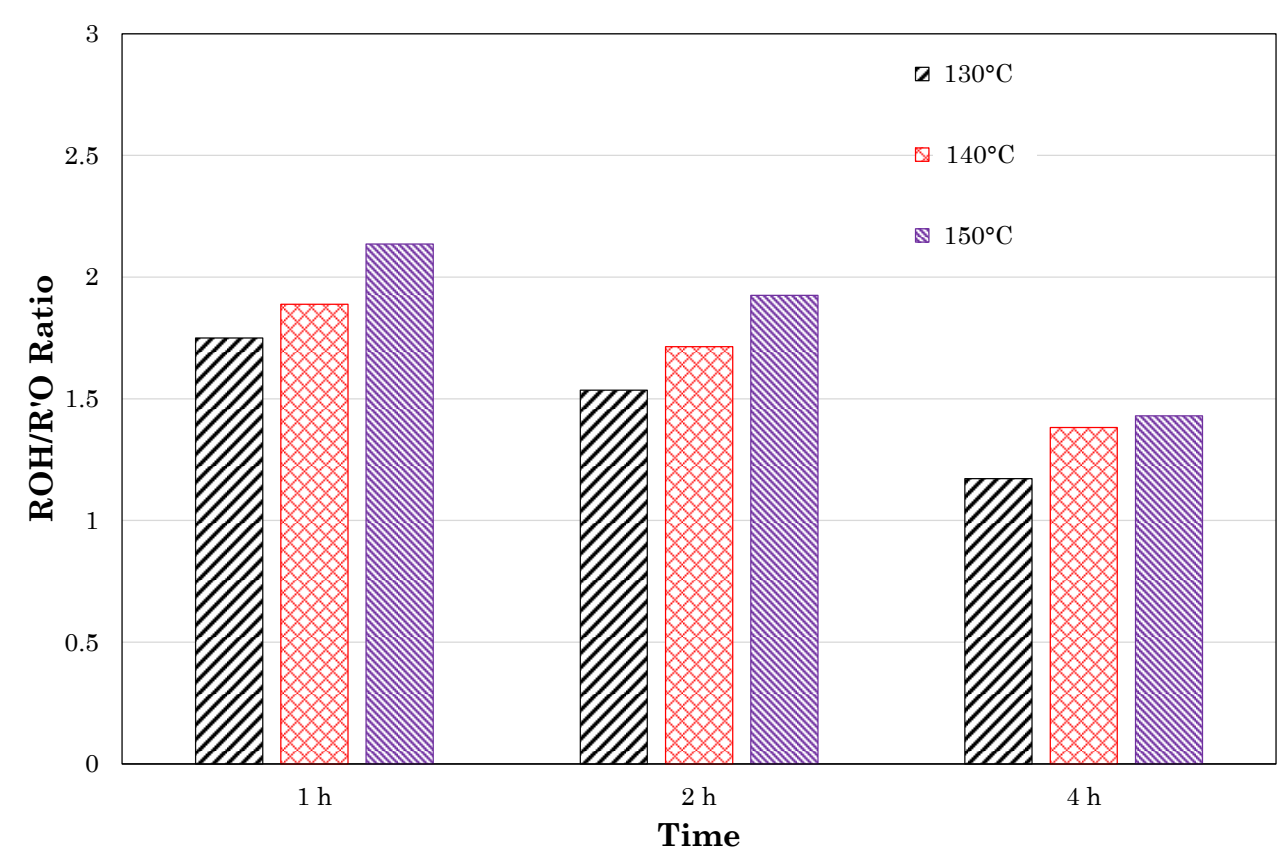

Figure 11. Effect of reaction temperature on ROH/R'O ratio. $P: 30$ bar, $y_{\mathrm{O}_{2} \text {,in }}: 0.05$, $C_{s-\mathrm{BuMB}}: 3.7 \mathrm{~mol} \%, C_{\mathrm{DTBP}}: 10 \mathrm{vol} \%, 15 \mathrm{~g} \mathrm{UOP}$ sieve.

4.8. Influence of the source of molecular sieve on reactor performance

The performance of two commercially available synthetic 3A molecular sieves were compared under identical experimental conditions: type 3A sieve sourced from Honeywell UOP (Sigma-

512 Aldrich) and ACROS Organics (Fisher Scientific). Figure 12 shows the results obtained during 513 the oxidation of $n$-pentane at $150^{\circ} \mathrm{C}$ with 3.7 and $5.4 \mathrm{~mol} \%$ sec-butyl metaborate and $15 \mathrm{~g}$ of ACROS Organics molecular sieve. These experimental runs were carried out under the same conditions as the borate-assisted oxidation results presented in Table 2 with the same quantity of UOP type 3A sieve.

Figure 12(a) shows that the total yield of the oxidation products are lower than for the equivalent experimental run in Table 2 utilising same amount of UOP sieve. For the experiment with $3.7 \mathrm{~mol} \% \mathrm{~s}$-BuMB, total yield of products after two hours are $4.14 \%$ and $4.65 \%$ for the AO sieve and UOP sieve, respectively. After 8 hours, the corresponding values were $13.82 \%$ and $16.2 \%$. For higher sec-butyl metaborate concentration of $5.4 \mathrm{~mol} \%$, the overall yield of oxidation products were $3.69 \%$ and $4.59 \%$ after two hours for the AO and UOP sieve, respectively. These results indicate that the UOP sieve probably exert some catalytic effects on the oxidation process compared to the $\mathrm{AO}$ adsorbent, leading to less inhibition of the oxidation in the case of the former. 

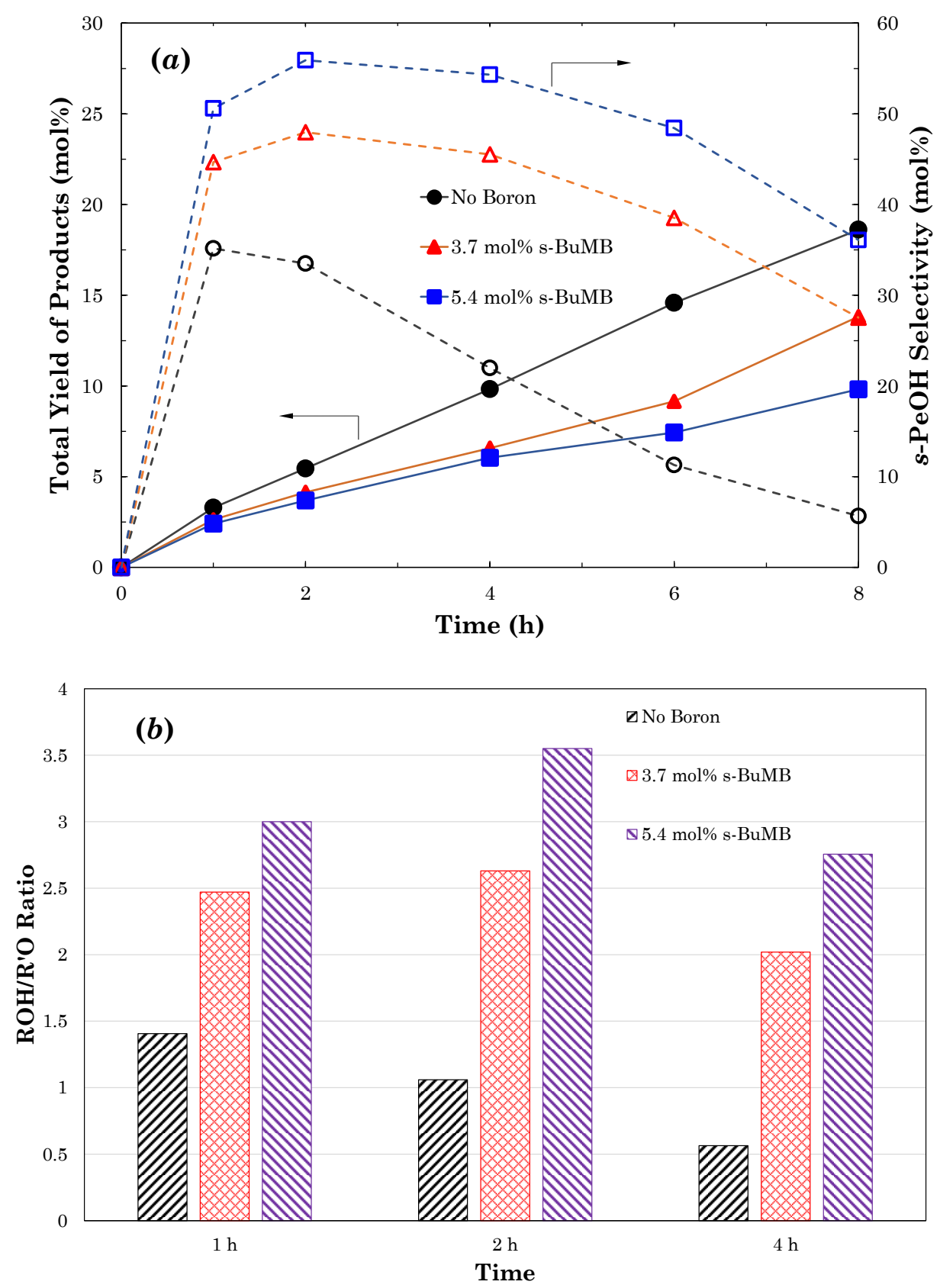

Figure 12. Effect of boron concentration on the oxidation of $n$-pentane. $T: 150^{\circ} \mathrm{C}, P: 30$ bar, $y_{\mathrm{O}_{2}, i n}: 0.05, C_{\mathrm{DTBP}}: 10 \mathrm{vol} \%, 15 \mathrm{~g} \mathrm{AO}$ sieve.

528 Furthermore, Figure 12(a) shows that selectivity to sec-pentanols is higher for the borateassisted oxidations with the ACROS Organics sieve than for oxidation with the UOP sieve shown in Table 2. For example, with 3.7 and $5.4 \mathrm{~mol} \% \mathrm{~s}$-BuMB and ACROS Organics sieve, selectivity to sec-pentanols is 47.9 and $55.9 \%$ after 2 hours, respectively, compared to $46.4 \%$ and $49.4 \%$ for the UOP sieve. After 8 hours, the alcohol selectivities decrease to 27.5 and $36.1 \%$ for the ACROS Organics adsorbents, while for the UOP sieve the selectivities were 26.3 
and $31.7 \%$. In addition, the pentanol-to-pentanone ratios in Figure $12(b)$ for the ACROS Organics sieve are significantly higher than for the oxidation runs utilising the UOP sieve, shown in Figure 10. Maximum ROH/R'O ratio with the ACROS Organics sieve were obtained after two hours, and these correspond to 2.63 and 3.55 for oxidation with 3.7 and $5.4 \mathrm{~mol} \% \mathrm{~s}$ BuMB, respectively, compared to 2.14 and $2.37 \%$ for the same concentrations of boron used with the UOP adsorbents, as shown in Figure 10.

Overall, the ACROS Organics sieve gives significantly higher alcohol selectivity and alcoholto-ketone ratio but slightly lower yield compared to the UOP sieve. A possible explanation for the observed differences in performance is given below.

Molecular sieves are synthetic zeolites or crystalline aluminosilicates; the type 3A sieve can be chemically represented by the empirical formula

$$
x \mathrm{~K}_{2} \mathrm{O} \cdot(1-x) \mathrm{Na}_{2} \mathrm{O} \cdot \mathrm{Al}_{2} \mathrm{O}_{3} \cdot 2 \mathrm{SiO}_{2} \cdot y \mathrm{H}_{2} \mathrm{O}
$$

where $x$ is the fraction of potassium ions, typically between 40 and $100 \%$.

The composition (i.e. silica-to-alumina ratio and metal ion content) and structure of molecular sieves have been shown to strongly influence their adsorptive properties as well as surface acidity and catalytic activity. Lin et al. [60] showed that the composition of $\mathrm{Na}^{+}$and $\mathrm{K}^{+}$in type $3 \mathrm{~A}$ sieve significantly affects the adsorption of water. The authors reported that due to site preferences for adsorbed water molecules in the zeolite framework, the capacity of $3 \mathrm{~A}$ sieves at low water vapour pressures $(<0.03 \mathrm{kPa})$ increases as the ratio of $\mathrm{K}^{+}$to $\mathrm{Na}^{+}$increases, however, the opposite effect is observed at higher water vapour pressures, i.e. UOP 4A sieve $\left(100 \% \mathrm{Na}^{+}\right)$outperforms a standard UOP $3 \mathrm{~A}$ sieve and a K-modified sieve, with $40 \%$ and $0 \%$ $\mathrm{Na}^{+}$, respectively. Furthermore, the solid-acid property and catalytic activity of molecular sieves are widely known [61]. The catalytic property of sieves arise from the surface Brønsted and Lewis acid sites inherent in their structures, which are readily regenerated on dehydration and neutralized on rehydration. The activity of sieves has been exploited to effect a wide range of acid-catalyzed hydrocarbon transformation reactions such as alcohol dehydration, isomerisation of alkanes, and polymerisation of olefins. According to Norton [62], the solidacidity, and hence catalytic activity, of type A molecular sieves for olefin polymerisation follows the order $3 \mathrm{~A}<4 \mathrm{~A}<5 \mathrm{~A}$, which reflects the increasing acidity of the metal ions present in the sieves, viz. $\mathrm{K}^{+}<\mathrm{Na}^{+}<\mathrm{Ca}^{2+}$. 
In general, metal ions can act as Lewis acids by coordinating to water or Lewis bases through the acceptance of a lone pair of electrons to form a hydrated metal ion or complex. The Lewis acid strength of a metal ion is dependent on its ability to attract electrons, which in turn is influenced by the size and charge of the ion [63]. Thus, the smaller the ionic radius of a cation, the stronger its Lewis acidity, making $\mathrm{Na}^{+}$a stronger Lewis acid than $\mathrm{K}^{+}$. Furthermore, the higher the positive charge on a metal ion, the more acidic it is due to stronger attraction on the electron density, hence $\mathrm{Al}^{3+}$ is a stronger Lewis acid than $\mathrm{Ca}^{2+}$, which in turn is more acidic than $\mathrm{Na}^{+}$and $\mathrm{K}^{+}$.

From the foregoing discussions, the observed differences in performance of the $3 \mathrm{~A}$ molecular sieves used in the present study may be connected with variations in the composition of the adsorbents. Indeed, based on the information provided in the product data sheet by the suppliers, the UOP type $3 \mathrm{~A}$ sieve has $60 \%$ potassium ion content $\left(\mathrm{K}^{+} / \mathrm{Na}^{+}=1.5\right)$ while the ACROS Organics 3A sieve contains $45 \%$ potassium ions $\left(\mathrm{K}^{+} / \mathrm{Na}^{+}=0.82\right)$. The silica-toalumina ( $\mathrm{Si} / \mathrm{Al})$ ratio for both materials is 1 . As a result of its higher $\mathrm{Na}^{+}$content, the ACROS Organic sieve probably has stronger surface Lewis acidity, and provides better in situ adsorption of the water formed, and thus better hydrolytic protection for sec-pentyl borates. This may in turn be attributed to the much improved sec-pentanol selectivity observed during oxidation with the ACROS Organics sieve compared to the UOP sieve.

\section{Conclusions}

The selective oxidation of $n$-pentane in the liquid phase assisted with a peroxide initiator and boron Lewis acid in the presence of a moisture adsorbent has been successfully demonstrated. This concept gives a significantly improved performance compared to the oxidation without the additives. The radical initiator increased the initial rate of oxidation thereby facilitating high product yield, the boron compounds promoted the formation of alcohols and subsequently minimised their over-oxidation by trapping them in the form of sec-pentyl borates, which are more stable to oxidation, while the molecular sieve 3A trapped the inhibiting water formed by adsorption, thus ensuring high selectivity to sec-pentanols.

Process parameters, including temperature, oxygen content in the feed gas, and initiator and boron concentrations, have a considerable effect on the rate of oxidation and product distribution. Thus, a complex interrelationship exists between the different parameters 
investigated in this work and their effect on the reactor performance. Overall, an optimum secpentanol selectivity of 56\% with an alcohol-to-ketone ratio of 3.6:1 and a total yield of $3.69 \%$ was obtained for pentane oxidation at $150^{\circ} \mathrm{C}, 30$ bar total pressure using a feed gas containing 5 vol\% oxygen, with 10 vol\% DTBP initiator, 5.4 mol\% s-BuMB and 15 g ACROS Organics 3A molecular sieve.

From a practical viewpoint, the concept demonstrated in this work can, in principle, be applied to other light alkanes in the $\mathrm{C}_{1}-\mathrm{C}_{9}$ range. This has the potential to enable the large-scale utilisation of cheaper feedstock for commodity chemical production. The alcohols formed in the process can be recovered as final products and utilised directly or they could be converted to other products such as olefins via dehydration, esters by reacting with an acid, ethers by partial dehydration, or heavier products by condensation over basic catalysts. Another possibility is direct processing of the borate esters from the reactor by thermal decomposition at around $300^{\circ} \mathrm{C}$ into olefins without first recovering the alcohols by hydrolysis. Overall, this process may have some commercial utility, hence further improvements in alcohol selectivity will make the process concept even more attractive.

Finally, the work presented in this paper has been filed as a patent application [64].

\section{Acknowledgement}

S.M. Aworinde gratefully acknowledges scholarship award from Cambridge Trust for his PhD. This research project was funded under a collaboration agreement between ExxonMobil Research and Engineering Company and the University of Cambridge.

\section{Nomenclature}

$C$

Concentration (mol\%, vol\%, $\mathrm{mol} \mathrm{L}^{-1}$ )

DTBP

Di-tert-butyl peroxide
$\Delta H_{r}^{\mathrm{o}}$
Standard enthalpy of reaction $\left(\mathrm{kJ} \mathrm{mol}^{-1}\right)$

LOC

Limiting oxygen concentration (vol\%)

$P \quad$ Total pressure (bar)

$629 \mathrm{PeO}$

Pentanones

$\mathrm{RH}$

Alkane

$\mathrm{ROOH}$

Alkyl hydroperoxide 


\begin{tabular}{|c|c|c|}
\hline 632 & \multicolumn{2}{|c|}{$S \quad$ Selectivity (\%) } \\
\hline 633 & \multicolumn{2}{|c|}{$s$-BuMB $\quad s e c$-Butyl metaborate } \\
\hline 634 & \multicolumn{2}{|c|}{$s-\mathrm{PeOH} \quad s e c$-Pentanol } \\
\hline 635 & \multicolumn{2}{|c|}{$T \quad$ Temperature $\left({ }^{\circ} \mathrm{C}\right)$} \\
\hline 636 & \multicolumn{2}{|c|}{ TiPrB $\quad$ Triisopropyl borate } \\
\hline 637 & \multicolumn{2}{|c|}{$Y \quad$ Yield $(\%)$} \\
\hline 638 & \multicolumn{2}{|c|}{ References } \\
\hline $\begin{array}{l}639 \\
640\end{array}$ & [1] & $\begin{array}{l}\text { J.H. Teles, I. Hermans, G. Franz, R.A. Sheldon, Oxidation, Ullmann's Encyclopedia of } \\
\text { Industrial Chemistry (2015). }\end{array}$ \\
\hline $\begin{array}{l}641 \\
642\end{array}$ & {$[2]$} & $\begin{array}{l}\text { P. Arpentinier, F. Cavani, F. Trifirò, The Technology of Catalytic Oxidations: } \\
\text { Chemical, Catalytic and Engineering Aspects, Technip, Paris, } 2001 .\end{array}$ \\
\hline $\begin{array}{l}643 \\
644\end{array}$ & [3] & $\begin{array}{l}\text { S. Matar, L.F. Hatch, Chemistry of Petrochemical Processes, 2nd ed., Gulf Publishing, } \\
\text { Houston, } 2000 .\end{array}$ \\
\hline $\begin{array}{l}645 \\
646\end{array}$ & {$[4]$} & $\begin{array}{l}\text { S.A. Korili, P. Ruiz, B. Delmon, Oxidative dehydrogenation of } n \text {-pentane on } \\
\text { magnesium vanadate catalysts, Catal. Today. } 32 \text { (1996) 229-235. }\end{array}$ \\
\hline $\begin{array}{l}647 \\
648 \\
649\end{array}$ & {$[5]$} & $\begin{array}{l}\text { V.A. Zazhigalov, J. Haber, J. Stoch, B.D. Mikhajluk, A.I. Pyatnitskaya, G.A. } \\
\text { Komashko, I.V. Bacherikova, A novel route in partial oxidation of } n \text {-pentane over the } \\
\text { VPO catalysts: Formation of citraconic anhydride, Catal. Lett. } 37 \text { (1996) 95-99. }\end{array}$ \\
\hline $\begin{array}{l}650 \\
651 \\
652\end{array}$ & {$[6]$} & $\begin{array}{l}\text { G. Centi, J. Lopez-Nieto, D. Pinelli, F. Trifirò, Synthesis of phthalic and maleic } \\
\text { anhydrides from } n \text {-pentane. 1. Kinetic analysis of the reaction network, Ind. Eng. } \\
\text { Chem. Res. } 28 \text { (1989) 400-406. }\end{array}$ \\
\hline $\begin{array}{l}653 \\
654 \\
655\end{array}$ & [7] & $\begin{array}{l}\text { A.E. Shilov, G.B. Shul'pin, Activation and Catalytic Reactions of Saturated } \\
\text { Hydrocarbons in the Presence of Metal Complexes, Kluwer Academic Publishers, } \\
\text { Dordrecht, } 2000 .\end{array}$ \\
\hline $\begin{array}{l}656 \\
657 \\
658\end{array}$ & [8] & $\begin{array}{l}\text { M. Freund, R. Csikós, S. Keszthelyi, G. Mózes, Paraffin Products: Properties, } \\
\text { Technologies, Applications, in: G. Mózes (Ed.), Dev. Pet. Sci. Vol. 14, Elsevier, } \\
\text { Amsterdam, 1982: pp. 13-70. }\end{array}$ \\
\hline $\begin{array}{l}659 \\
660\end{array}$ & {$[9]$} & $\begin{array}{l}\text { J.A. Labinger, J.E. Bercaw, Understanding and exploiting C-H bond activation, } \\
\text { Nature. } 417 \text { (2002) 507-514. }\end{array}$ \\
\hline $\begin{array}{l}661 \\
662 \\
663\end{array}$ & [10] & $\begin{array}{l}\text { J.A. Howard, Oxidation, in: J.J. Zuckerman, D.N. Arlan (Eds.), Inorganic Reactions } \\
\text { and Methods: Reactions Catalyzed by Inorganic Compounds Vol. 5, Wiley-VCH, New } \\
\text { York, 1993: pp. 398-407. }\end{array}$ \\
\hline 664 & {$[11]$} & F. Broich, Oxidation reactions in petrochemistry, Chem. Ing. Tech. 34 (1962) 45-61. \\
\hline $\begin{array}{l}665 \\
666 \\
667\end{array}$ & {$[12]$} & $\begin{array}{l}\text { G.S. Mishra, A.J.L. Pombeiro, Oxyfunctionalization of } n \text {-pentane and } n \text {-hexane by } \\
\text { oxovanadium complexes supported on carbamated modified silica gel, Appl. Catal. A } \\
\text { Gen. } 304 \text { (2006) 185-194. }\end{array}$ \\
\hline $\begin{array}{l}668 \\
669 \\
670\end{array}$ & {$[13]$} & $\begin{array}{l}\text { J.R.L. Smith, Y. Iamamoto, F.S. Vinhado, Oxidation of alkanes by iodosylbenzene } \\
\text { (PhIO) catalysed by supported Mn(III) porphyrins: Activity and mechanism, J. Mol. } \\
\text { Catal. A Chem. } 252 \text { (2006) 23-30. }\end{array}$ \\
\hline
\end{tabular}


[14] J.M. Thomas, R. Raja, G. Sankar, R.G. Bell, Molecular-sieve catalysts for the selective oxidation of linear alkanes by molecular oxygen, Nature. 398 (1999) 227-230.

[15] J.F. Bartoli, O. Brigaud, P. Battioni, D. Mansuy, Hydroxylation of linear alkanes catalysed by iron porphyrins: Particular efficacy and regioselectivity of perhalogenated porphyrins, J. Chem. Soc., Chem. Commun. 0 (1991) 440-442.

[16] S.M. Aworinde, A.M. Schweidtmann, A.A. Lapkin, The concept of selectivity control by simultaneous distribution of the oxygen feed and wall temperature in a microstructured reactor, Chem. Eng. J. 331 (2018) 765-776.

[17] W.G. Woods, R.J. Brotherton, Oxidations of Organic Substrates in the Presence of Boron Compounds, in: R.J. Brotherton, H. Steinberg (Eds.), Progress in Boron Chemistry Vol. 3, Pergamon Press, Oxford, UK, 1970: pp. 1-115.

[18] A.N. Bashkirov, V.V. Kamzolkin, K.M. Sokova, T.P. Andreyeva, The mechanism of the liquid-phase oxidation of paraffinic hydrocarbons, in: N.M. Emanuel' (Ed.), Oxidation of Hydrocarbons in the Liquid Phase, Pergamon Press Ltd, Oxford, 1965: pp. 183-193.

[19] A.N. Bashkirov, V.V. Kamzolkin, Synthesis of higher aliphatic alcohols by direct oxidation of paraffinic hydrocarbons, in: Proc. 5th World Pet. Cong., World Petroleum Cogress, New York, 1959: p. Sec. IV, Paper 15, 175-183.

[20] K. Weissermel, H.-J. Arpe, Industrial Organic Chemistry, 3rd ed., Wiley-VCH, Weinheim, 1997.

[21] R.A. Sheldon, J.. Kochi, Metal-Catalyzed Oxidations of Organic Compounds: Mechanistic Principles and Synthetic Methodology Including Biochemical Processes, Academic Press, Inc., New York, 1981.

[22] V.A. Itskovich, P. Lak Von, T.G. Maslayanskaya, L.P. Tsudikova, V.V. Fokin, Oxidation of naphthene hydrocarbons in the presence of boron compounds, Neftekhimiya. 18 (1978) 603-608.

[23] H. Sakaguchi, E. Niki, Y. Kamiya, Decomposition of hydroperoxides by boric acid anhydride in solution. Electrophilic hydroxylation of the solvent, J. Chem. Soc., Perkin Trans. II. 3 (1976) 855-858.

[24] F.I. Novak, V.V. Kamzolkin, Y.A. Talyzenkov, A.N. Bashkirov, Mechanism of the effect of boric acid on liquid-phase oxidation of paraffin hydrocarbons, Neftekhimiya. 7 (1967) 248-253.

[25] K. Griesbaum, A. Behr, D. Biedenkapp, H.-W. Voges, D. Garbe, C. Paetz, G. Collin, D. Mayer, H. Hoke, Hydrocarbons, Ullmann's Encyclopedia of Industrial Chemistry (2012).

[26] P. Arpentinier, Synthesis of intermediates for the petrochemical industry: Oxidation processes in liquid phase with oxygen, in: C. Giavarini, F. Trifiro (Eds.), Encyclopedia of Hydrocarbons Vol II Refining and Petrochemicals, ENI: Istituto Della Enciclopedia Italiana, Roma, 2006: pp. 636-660.

[27] C.L. Edwards, Polyoxyethylene alcohols, in: N.M. van Os (Ed.), Nonionic Surfactants: Organic Chemistry, Marcel Dekker, New York, 1998: pp. 98-99.

[28] G. Strauss, K. Schneider, W. Jacquemin, Production of alcohols, US3651153, 1972. 
[29] C.N. Winnick, Oxidation of hydrocarbons to borate esters, US3243449, 1966.

[30] N.M. Emanuel, E.T. Denisov, Z.K. Maizus, Liquid-Phase Oxidation of Hydrocarbons, Plenum Press, New York, 1967.

[31] I. Hermans, Overview of radical chain oxidation chemistry, in: S.. Stahl, P.L. Alsters (Eds.), Liquid Phase Aerobic Oxidation Catalysis: Industrial Applications and Academic Perspectives, 1st ed., Wiley-VCH, Weinheim, 2016: pp. 3-14.

[32] T. Mill, D.G. Hendry, Kinetics and mechanisms of free radical oxidation of alkanes and olefins in the liquid phase, in: C.H. Bamford, C.F.H. Tipper (Eds.), Compr. Chem. Kinet., Elsevier, Amsterdam, 1980: pp. 1-87.

[33] R.A. Sheldon, J.K. Kochi, Metal-catalyzed oxidations of organic compounds in the liquid phase: A mechanistic approach, in: D.D. Eley, H. Pines, P.B. Weisz (Eds.), Adv. Catal., Academic Press, New York, 1976: pp. 272-413.

[34] G.H. Twigg, The mechanism of liquid-phase oxidation, Chem. Eng. Sci. Suppl. 3 (1954) 5-16.

[35] T. Mill, F. Mayo, H. Richardson, K. Irwin, D.L. Allara, Gas- and liquid-phase oxidations of $n$-butane, J. Am. Chem. Soc. 94 (1972) 6802-6811.

[36] E.T. Denisov, I.B. Afanas'ev, Oxidation and antioxidants in organic chemistry and biology, Taylor \& Francis, Boca Raton, 2005.

[37] A. Kunzelmann, G. Lauterbach, V.M. Potekhin, W. Pritzkow, W. Schmidt-Renner, L.F. Vasina, On the mechanism of hydroperoxide decomposition by boric acid derivatives, J. Prakt. Chemie. 328 (1986) 772-776.

[38] N.M. Emanuel, Kinetics and mechanism of chain reactions of liquid-phase oxidation of hydrocarbons, Izv. Akad. Nauk SSSR, Ser. Khim. 5 (1974) 1010-1023.

[39] M.N. Puring, V.M. Poteckhin, V.A. Itskovich, V.B. Lebedev, Complex formation of 1methylcyclohexylhydroperoxide with esters of boric acid, Zhurnal Prikl. Spektrospii. 22 (1975) 271-275.

[40] P.F. Wolf, R.K. Barnes, The borate ester induced decomposition of alkyl hydroperoxides. The epoxidation of olefins by electrophilic oxygen, J. Org. Chem. 34 (1969) 3441-3445.

[41] N. Kurata, K. Koshida, Higher sec-alcohols, ethoxylates, Hydrocarb. Process. 57 (1978) 145-151.

[42] K.M. Sokova, G.A. Zelenaya, A.N. Bashkirov, Oxidation of cyclododecene with molecular oxygen in the presence of boric acid, Neftekhimiya. 16 (1976) 445-451.

[43] A.N. Bashkirov, V.V. Kamzolkin, K.M. Sokova, T.P. Andreyeva, V.V. Korneva, L.I. Zakharkin, The production of cyclododecanol by the liquid-phase oxidation of cyclododecane, Neftekhimiya. 1 (1961) 527-534.

[44] F. Broich, H. Grasemann, The air oxidation of cyclic hydrocarbons in the presence of boric acid: A contribution to the elucidation of the reaction mechanism, Erdöl Und Kohle-Erdgas-Petrochemie. 18 (1965) 360-364.

[45] D.A. Crowl, J.F. Louvar, Chemical Process Safety: Fundamentals with applications, 2nd ed., Prentice Hall, New Jersey, 2002. 
[46] P. Arpentinier, F. Cavani, F. Trifirò, The Technology of Catalytic Oxidations: Safety Aspects, Technip, Paris, 2001.

[47] M.F. Lappert, Cyclic organic boron compounds. Part I. Preparation, characterisation, and stability of esters of metaboric acid., J. Chem. Soc. 0 (1958) 2790-2793.

[48] A. de Klerk, Continuous-mode thermal oxidation of Fischer - Tropsch waxes, Ind. Eng. Chem. Res. 42 (2003) 6545-6548.

[49] B.D. Boss, R.N. Hazlett, $n$-Dodecane oxidation - elucidation by internal reference techniques, Ind. Eng. Chem. Prod. Res. Dev. 14 (1975) 135-138.

[50] A.W. Dawkins, Oxidation of $n$-paraffins, Eur. Chem. News, Norm. Paraffins Suppl. 10 (1966) 49-58.

[51] B.D. Boss, R.N. Hazlett, Oxidation of hydrocarbons in the liquid phase: $n$-Dodecane in a borosilicate glass chamber at $200^{\circ} \mathrm{C}$, Can. J. Chem. 47 (1969) $4175-4182$.

[52] H. Sakaguchi, Y. Kamiya, N. Ohta, Autoxidation of hydrocarbons in the presence of boric acids: Decomposition of aromatic hydroperoxides, Bull. Jap. Pet. Inst. 14 (1972) 71-75.

[53] I.B. Sivaev, V.I. Bregadze, Lewis acidity of boron compounds, Coord. Chem. Rev. 270 (2014) 75-88.

[54] G. Lauterbach, W. Pritzkow, T.D. Tien, V. Voerckel, Studies on the decomposition of alkyl hydroperoxides by different catalysts, J. Prakt. Chemie. 330 (1988) 933-946.

[55] P.F. Wolf, J.E. McKeon, D.W. Cannell, Mechanisms of the the borate ester induced decomposition of alkyl hydroperoxides, J. Org. Chem. 40 (1975) 1875-1882.

[56] M.A. McMahon, H. Chafetz, Alcohol manufacture, US3410913, 1968.

[57] G.E. Illingworth, Preparation of alcohols, US3384672, 1968.

[58] R.A. Sheldon, J.A. van Doorn, Boron-catalysed epoxidation of olefins with tert-butyl hydroperoxide, J. Catal. 34 (1974) 242-245.

[59] M.A. Beckett, M.P. Rugen-Hankey, G.C. Strickland, K.S. Varma, Lewis acidity in haloalkyl orthoborate and metaborate esters, Phosphorus, Sulfur Silicon and Related Elements. 169 (2001) 113-116.

[60] R. Lin, A. Ladshaw, Y. Nan, J. Liu, S. Yiacoumi, C. Tsouris, D.W. DePaoli, L.L. Tavlarides, Isotherms for water adsorption on molecular sieve $3 \mathrm{~A}$ : Influence of cation composition, Ind. Eng. Chem. Res. 54 (2015) 10442-10448.

[61] K. Tanabe, M. Misono, H. Hattori, Y. Ono, New Solid Acids and Bases: Their Catalytic Properties, in: Stud. Surf. Sci. Catal. Vol. 51, Elsevier, Amsterdam, 1989: pp. $1-25$.

[62] C.J. Norton, Olefin polymerization over synthetic molecular sieves, Ind. Eng. Chem. Proc. Des. Dev. 3 (1964) 230-236.

[63] D.P.N. Satchell, R.S. Satchell, Quantitative aspects of Lewis acidity, Q. Rev. Chem. Soc. 25 (1971) 171-199.

[64] S.M. Aworinde, K. Wang, A.A. Lapkin, Oxidation of $\mathrm{C}_{1-9}$ alkanes, US62/592,825, 
793

2017.

794 


\section{Borate-assisted liquid-phase selective oxidation of $\boldsymbol{n}$-pentane}

Samson M. Aworinde, ${ }^{\text {a }}$ Kun Wang, ${ }^{\mathrm{b}}$ Alexei A. Lapkin ${ }^{\mathrm{a}, *}$

a Department of Chemical Engineering and Biotechnology, University of Cambridge, Philippa Fawcett Drive, Cambridge, CB3 OAS, United Kingdom

${ }^{\mathrm{b}}$ Corporate Strategic Research, ExxonMobil Research and Engineering Company,1545 US-

22 East, Annandale, NJ 08801, United States

\section{Supporting Information}

\section{List of Supporting Information}

1) An MS chromatogram of liquid products of $n$-pentane oxidation.

\section{An MS chromatogram of liquid products of $\boldsymbol{n}$-pentane oxidation.}

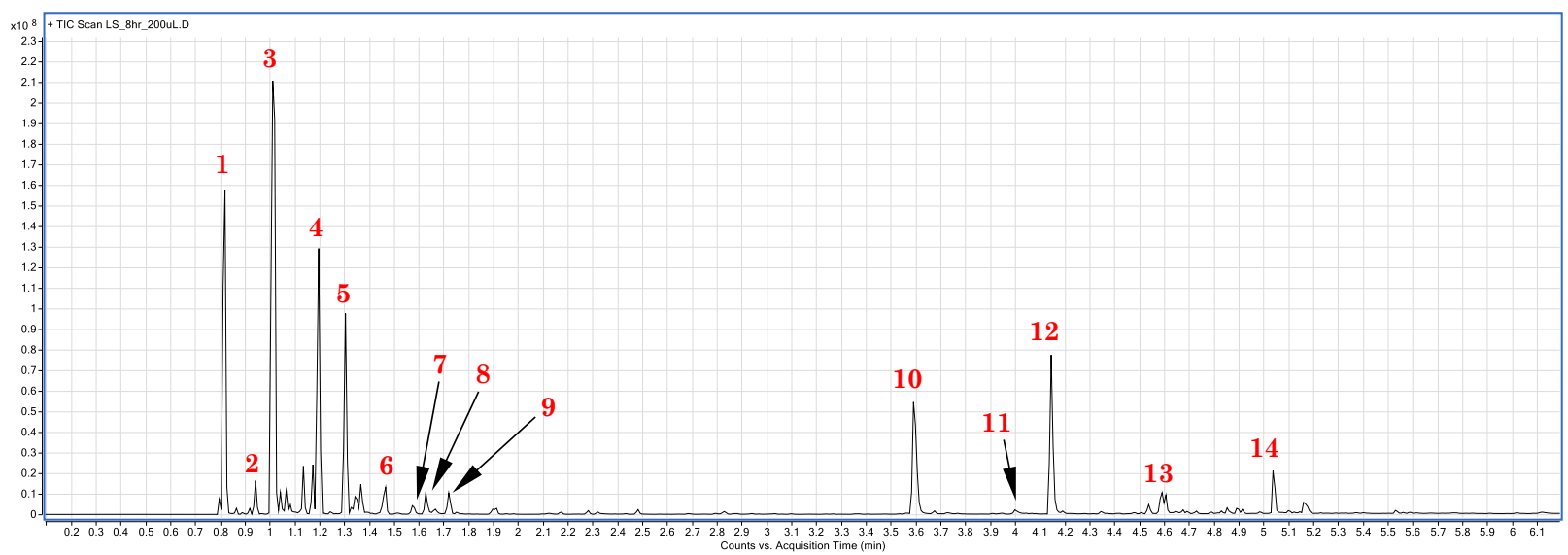

Figure S1. An MS chromatogram of liquid products of $n$-pentane oxidation after 8 hours of reaction.

1: $n$-pentane, 2: acetone, 3: ethyl acetate (solvent), 4: 2- and 3-pentanones, 5: 1,4difluorobenzene (internal standard), 6: 2-pentyl acetate, 7: 3-pentanol, 8: 2-pentanol, 9: 2pentyl propanoate, 10: acetic acid, 11: formic acid, 12: propanoic acid, 13: butanoic acid, 14: pentanoic acid. $T: 150^{\circ} \mathrm{C}, P: 30$ bar, $y_{\mathrm{O}_{2}, \text { in }}: 0.1,1$ vol\% DTBP. 